\title{
Mechanical Response and Deformation Mechanisms of Ferritic Oxide Dispersion Strengthened Steel Structures Produced by Selective Laser
}

\author{
Melting
}

Thomas Boegelein ${ }^{\mathrm{a}, \mathrm{b}, *}$, Sebastien N. Dryepondt ${ }^{\mathrm{b}}$, Amit Pandey ${ }^{\mathrm{b}, \grave{\dagger}}$, Karl Dawson $^{\mathrm{a}}$, Gordon J. Tatlock ${ }^{\mathrm{a}}$

${ }^{a}$ Centre for Materials and Structures, School of Engineering, University of Liverpool, L69 3GH, UK

${ }^{b}$ Materials Science and Technology Division, Oak Ridge National Laboratory, Oak Ridge, TN 37831, USA

* Corresponding author. Tel.: +44 (0) 151 - 795 2273; fax: +44 (0) 151 - 7944675.

E-mail addresses: t.boegelein@liv.ac.uk, thomas.boegelein@web.de (T. Boegelein).

† Present address: Reliability Division, Rolls Royce LG Fuel Cell Systems Inc., North Canton, OH 44224, USA. 


\begin{abstract}
Oxide dispersion strengthened (ODS) ferritic steels typically contain a fine dispersion of nanoscopic $\mathrm{Y}(\mathrm{Al}, \mathrm{Ti})$ oxides leading to an improvement in mechanical and physical properties. A rapid prototyping technique, selective laser melting (SLM), was successfully applied to consolidate as-mechanically alloyed ODS-PM2000 (Fe-19Cr-5.5Al-0.5Ti-0.5 $\mathrm{Y}_{2} \mathrm{O}_{3}$; all wt.\%) powder to fabricate solid and thin walled builds of different thickness. This work is intended to act as a first study to investigate the tensile response of such configurations at room temperature, using miniaturised test specimens along and perpendicular to the growth direction. The $0.2 \%$ offset yield strength (YS) of as-grown wall builds was inferior to conventional PM2000 alloy (recrystallized), but could be significantly increased by conducting post-build heat treatments. Young's modulus and yield strength showed anisotropy and were enhanced when testing perpendicular to the build growth direction. Electron backscatter diffraction (EBSD) revealed a strong [001] fibre texture along the growth direction, which explains the anisotropic behaviour. Additionally, studies on the morphology of the individual fracture surfaces, the grain structure of the cross section near this region and the size distribution of ODS particles in such builds were conducted. A fine dispersion of precipitates was retained in all SLM builds and findings suggest that a certain amount of $\mathrm{Y}$ is probably still in atomic solution in the as-grown condition and forms new small nanoscopic dispersoids during annealing, which lead to enhanced strengthening.
\end{abstract}

Keywords: Oxide dispersion strengthened alloys, rapid prototyping, tensile testing, anisotropy, transmission electron microscopy 


\section{Introduction}

Oxide dispersion strengthened (ODS) ferritic steels typically contain a fine homogeneous dispersion of thermally stable nanoscopic $\mathrm{Y}(\mathrm{Al}, \mathrm{Ti})$ oxides. These ceramic particles lead to an improvement in mechanical and physical properties, hence significantly increase the permitted operating temperature of components made of ODS materials compared to dispersoid-free alloys [1]. Al-containing ODS steels form a slow growing adherent alumina scale at high temperatures and thus offer extreme tolerance to oxidation [2] and the presence of a coarse microstructure after recrystallization is beneficial to creep strength [3]. Those excellent properties make Al-containing ODS steels candidates for applications in future conventional power plants [4,5], biomass combustion [6] and other high temperature applications [7]. Small ODS dispersoids also act as sink sites for detrimental transmutation He formed in the material under neutron irradiation $[8,9]$. However, $\mathrm{Al}$ forms unwanted long-lasting isotopes when exposed to nuclear radiation and, thus, Al-free ODS steels are considered for future fusion/fission applications $[10,11]$. This type of ODS steel is being used with a significantly smaller grain size than Al-containing variants, which increases tensile strength and ductility but lowers creep strength at high temperature [12]. The major strengthening mechanisms of ODS steels at low $\left(<\sim 700^{\circ} \mathrm{C}\right)$ temperatures were identified as solution strengthening, dispersoid (Orowan) strengthening and grain boundary strengthening; the individual contributions may vary significantly depending on the alloy composition, the micro and nanostructure, and temperature $[13,14]$. At elevated temperatures $\left(>\sim 700^{\circ} \mathrm{C}\right)$ thermally activated processes become more distinct, leading, for instance, to a significant drop of grain boundary strengthening, solution strengthening and changes in particle/dislocation interactions, and also the occurrence of creep effects [14]. Conventionally, ODS steels are fabricated through complex and inflexible powder metallurgical processes. This starts with mechanical alloying (MA), where powder raw materials are subject to repeated cold welding and fracture leading to dissolution of the alloying elements [15,16]. MA is followed by degassing, hot extrusion or hot isostatic pressing to consolidate the product, and sometimes 
hot and cold rolling steps followed by heat treatments. A recent study on the formation and evolution of oxide particles in Fe-14Cr-2W-0.3Ti alloys mechanically alloyed with $\mathrm{Y}_{2} \mathrm{O}_{3}$ or $\mathrm{Fe}_{2} \mathrm{Y}$ has shown that $\mathrm{Y}$, Ti and $\mathrm{O}$ are present in the matrix after ball milling, and the nanoclusters of Ti-Cr-O initially formed increase in size and become enriched in Y during the various consolidation steps as Y diffuses very slowly in the $\alpha$-Fe matrix [16]. Once ODS materials are molten, as is evident from the study of fusion welds [17], dispersoids agglomerate and slag off because of density differences between the dispersoids and the matrix. This leads to a loss in mechanical performance in the weld zone due to reduced particle strengthening. Thus, current research interest in this field has concentrated on the evaluation and the development of alternative fabrication and solid state joining techniques for ODS materials, as this would significantly increase their widespread use. Several joining processes have recently demonstrated potential feasibility in the ODS alloy environment, including friction-stir welding $[18,19]$, diffusion bonding [20], transient liquid-phase bonding [21] or pulsed plasma-assisted diffusion bonding [22]. Other alternatives are beam-based techniques, for instance electron beam welding [23] or laser beam welding. In particular, this latter technique has shown promising results as ODS particles could be retained in the bond zone $[24,25,26]$. These findings motivated a recent study by Walker et al. (2009) to use an additive manufacturing technique, selective laser melting, to consolidate as-MA ODS steel powder [27]. Selective laser melting (SLM) is a recent additive rapid prototyping development and the machine layout used to manufacture the builds for this study is illustrated in Fig. 1. Metal powder is used as build material and is delivered in a thin layer onto a substrate. This deposit slice is successively scanned with a finely focused laser beam leading to molten material fusing to an underlying substrate or to previously deposited material. For the present builds, the layer thickness of consolidated material was $\sim 50 \mu \mathrm{m}$. After these steps, the substrate lowers and the process repeats until the desired build is achieved. The thermal conditions near the fusion zone are obviously similar to conventional laser welding (conduction based). Due to localised heat input, there are strong cooling rates in the heat affected zone, which depend on several parameters, such as scanning velocity, laser spot size or thermal conductivity of the material [28]. Due to Marangoni type forces, caused by a strong thermal gradient in the melt pool and different 
coefficients of surface tension, constant stirring occurs under such conditions [29]. Thijs et al. demonstrated on the example of an $\mathrm{Al}$ alloy that sub-micron sized grains grow in an [100] orientation perpendicular to the liquidus/solidus interface. Favoured by successive re-melting of previously deposit material, grains become elongated in the same orientation growing through several deposited slices along the SLM build direction if the scanning directions remain unchanged [30]. Similar to other recent rapid prototyping technologies, SLM fabrication uses computer aided design (CAD), which allows a great level of design freedom and flexibility [31]. A number of build configurations can be produced with SLM including complex thin walled structures, coatings, solid builds, meshes and porous structures. Due to small melt pools and high cooling rates, SLM is a candidate technique to process ODS alloys. Walker et al. (2009) demonstrated that a fine dispersion of ODS precipitates can be retained under certain processing parameters by manufacturing thin walls using as-MA powder of PM2000, a FeCrAl ODS alloy [27]. The developed settings were recently successfully applied on the same material to fabricate a complex thin walled honeycomb structure. The build was subject to major investigations $[32,33]$ and the key results are summarised briefly. In the as-grown condition, there was a fine homogeneous dispersion of globular shaped precipitates, composed of different phases and probably amorphous regions, which had varying concentrations of elements, such as $\mathrm{O}, \mathrm{Al}, \mathrm{Ti}, \mathrm{Cr}, \mathrm{Fe}$ and $\mathrm{Y}$. A post-build heat treatment at $1200^{\circ} \mathrm{C}$ for one hour resulted in a change of such particulates into Al-Y oxides having typically one single phase. During annealing Y, which diffuses slowly in $\alpha$-Fe matrix becomes more mobile and might replace other elements included in the multi-phased precipitates, which simply diffuse into the surrounding matrix. The resulting particle size distribution changed during this annealing step. In the asgrown condition, the size distribution was similar to conventionally processed recrystallized PM2000, but after the heat treatment pre-existing precipitates coarsened and a dispersion of new fine oxides was observed. During this annealing step, precipitates present in the as-grown condition probably coarsen due to Ostwald ripening during which the free energy of a system decreases, while larger particles grow at the expense of smaller species by diffusion based interparticle migration processes [34-36]. Simultaneously, 
other fine particles nucleate and grow, probably due to a supersaturation of $\mathrm{Y}$ in the matrix prior to annealing.

In order to address some of the detrimental issues observed on previous builds, SLM processing parameters were optimised for the walls and solid builds. The mechanical tensile response and deformation mechanisms of these improved builds are the subject of this article.

However, in this study, the emphasis is placed on the mechanical tensile response and deformation mechanisms of these build configurations at room temperature, before conducting further studies and testing at elevated temperatures.

\section{Experimental details and materials}

\subsection{Manufacture of SLM Builds}

The study used commercial as-MA ODS-PM2000 powder, supplied by Plansee GmbH (Reutte, Austria); the nominal composition of the alloy is displayed in Table 1 according to the alloy datasheet and the composition was confirmed by an analysis using inductively coupled plasma optical emission spectrometry (ICP-OES).

Powder of the same batch was also SLM-consolidated by Walker et al. (2009) [27]. Detailed analyses on particle size and morphology were conducted in that work and a filling factor, which is the ratio of the density of solid material to the powder volume, of 0.46 was determined. Consequently, in order to produce a slice thickness of $50 \mu \mathrm{m}$ in the consolidated material, a powder layer thickness of $109 \mu \mathrm{m}$ was required. Hence, the powder was sieved with a stainless steel shaker having a $106 \mu \mathrm{m}$ mesh size in order to remove the coarser particle fraction. The powder was stored in a sealed container in dry conditions.

Chemical analysis conducted by ICP-OES, combustion and inert gas fusion (IGF) did not reveal any form of contamination. 
In the present study, an SLM system, type Realizer 100 machine from MTT Technologies, was used to fabricate the build configurations on a mild steel substrate. The machine was equipped with an $\mathrm{Yb}$ doped fibre laser, type YLR-200, from IPG Photonics with a wavelength of 1075-1095 nm. In the system, the laser beam with a power of $50 \mathrm{~W}$ was focused to focal position to a spot size of $\sim 100 \mu \mathrm{m}\left(\varnothing_{90 \%}\right)$ onto the powder layer and exhibited an approximate Gaussian distribution; determined using a SP620U beam profiler from Ophir Optronics Ltd. Laser scanning of individual slices of walls was conducted in continuous wave operation and a stop-and-go movement was applied. In order to grow individual layers of solid builds, parallel lines were scanned with a certain hatch distance between them using bidirectional vectors. For these builds, a cross hatching strategy was applied. Hence between two consecutive layers the scanning direction was altered by $90^{\circ}$. More details on such a scanning strategy is given elsewhere and it was shown in that work that this results in a reduction of a texture along the build and scanning directions [30], which consequently minimises anisotropical properties of such structures. For the wall fabricated with three parallel laser scans, the outer lines were scanned prior to the central line for each deposit layer to improve build integrity. The SLM build process took place in a closed chamber in inert (Ar) atmosphere and the initial level of $\mathrm{O}$ was between 200 and 300 ppm, which dropped below the level of detection during fabrication of the first seven layers, probably due to oxidation near the fusion zone. A gas system ensured a constant flow of the gas over the build area and builds were fabricated in sequence, always moving upstream to avoid incorporation of sputtered material into the layer. The build configurations were optimised in terms of surface quality, build defects and small melt pools to promote fast cooling rates in order to minimize coarsening, agglomeration and slagging of dispersoids. Solid blocks had the dimensions of 25.4 (length) $\times 10$ (width) $\times 12$ (height) $\mathrm{mm}$. Walls were fabricated with one, two and three parallel laser scans per deposit layer which produced $150 \mu \mathrm{m}$ (SLM wall 1), $260 \mu \mathrm{m}$ (SLM wall 2) and $330 \mu \mathrm{m}$ (SLM wall 3) thick walls respectively. Wall builds had the dimensions of 24(length) $\times 12$ (height) $\mathrm{mm}$ and 12 (length) $\times 12$ (height) $\mathrm{mm}$. The surface finish of the walls (determined using a surface profiler, type OSP 100, Uniscan Instruments) was in a range of $R_{a}=5-12 \mu \mathrm{m}$, while the relative density was above $99.5 \%$ for the wall structures and above $98.5 \%$ for the solid builds determined 
by optical microscopy of cross sections. Fig. 2 shows the fabricated blocks and wall structures, which were stabilized by side ribs to avoid deformation during processing due to residual stresses and due to the friction between the recoating mechanism and consolidated material.

\subsection{Reference materials and sample preparation}

Conventionally produced PM2000 (reference material; supplied by Plansee) was provided in the form of an as-extruded non recrystallized bar. A sheet with the dimensions 62 (length) $\times 24$ (width) $\times 0.4$ (thickness) $\mathrm{mm}$ was sectioned from this bar along the extrusion direction using wire electric discharge machining (EDM). This procedure slightly altered the as-extruded fine grained microstructure near the cut line only to a depth of approximately $10 \mu \mathrm{m}$, hence the expected effect on the trials was minor. The SLM builds were removed from the substrate by the same process and all parts were chemically cleaned prior to further work.

In this study the tensile behaviour of SLM samples in the as-grown and annealed conditions will be compared with those of the reference PM2000 material in the as-extruded and recrystallized states. In this regard, half of the samples were sealed in quartz ampoules, which were evacuated with a vacuum of $<10^{-4}$ torr and filled with an $\mathrm{Ar}-5 \mathrm{vol} . \% \mathrm{H}_{2}$ atmosphere to avoid oxidation during annealing. $1 \mathrm{~h}$ isothermal heat treatments were conducted in a horizontal tube furnace at $1200^{\circ} \mathrm{C}$ for the SLM builds (to stimulate modifications of precipitates) and at $1380^{\circ} \mathrm{C}$ for the reference material, which is the standard recrystallization treatment for PM2000.

The micro tensile test specimens used in this work had a total length of $4.3 \mathrm{~mm}$ and a gauge section of $1.7 \mathrm{~mm}$ (long) and $0.83 \mathrm{~mm}$ wide, whereas the thickness of wall builds was not modified from the asgrown condition. One example, showing SLM wall 1 with a thickness of $150 \mu \mathrm{m}$, is illustrated in Fig. $3 \mathrm{a}$. Despite the small size of the specimens there were still several grains in the gauge section, which is illustrated in Fig. $3 \mathrm{~b}$ for the same sample, which was cross sectioned near the approximate centre 
position. All test specimens were cut out by EDM parallel or perpendicular to the build direction for the SLM builds, and parallel or perpendicular to the extrusion direction for the reference material, as illustrated in Fig. 4.

\subsection{Tensile Testing of Microspecimens}

Microtensile tests were conducted using an experimental set-up as described in detail elsewhere [37]. The main components were a stepper motor, type NEMA 23 (National Instruments), a $111.1 \mathrm{~N}$ (25 lbs) load cell and a custom slider linear air bearing. In order to minimise vibrations, the test set-up was fixed on an air table. Experiments were performed under uniaxial tension with a few unloading and reloading sequences. In some cases it was found that, on initial load, the elastic range deviated from linearity. Hence unload-reload sequences were used to determine the Young's moduli after certain levels of strain, as was suggested by Benito et al. [38]. The load and displacement were monitored and recorded by a computer programme (LabView ${ }^{\circledR}$, National Instruments). Tests were performed under a displacement rate of $0.005 \mathrm{~mm} / \mathrm{s}$, corresponding to a deformation rate of $\sim 0.003 \mathrm{~s}^{-1}$, and specimen plan view images were captured at every second using a complementary metal-oxide-semiconductor (CMOS) camera. These images were post processed to calculate the 2D strain maps using a Matlab®-based digital image correlation (DIC) program as described elsewhere [37,39-41]. Each build configuration was tested twice in order to improve statistical reliability. During testing, it was found that slight slip of the tensile specimens occurred within the grips, which lead to deformation of the grip section and axial displacement of the area monitored by DIC along the test direction. The $0.2 \%$ offset yield stress (YS) is determined as a parallel offset to the elastic region in the stress-strain plot and is therefore less sensitive to minor deviations of the acquired strain values. In this work, the overall YS was determined from sets of specimens, but the ultimate tensile strength (UTS), the total elongation and the Young's modulus was measured only on those specimens which did not suffer from clamp slip issues. Post test imaging and 
analysis was only conducted on specimens which had been only marginally affected by slip within the grips. As-extruded reference material exhibited a sub-micron sized uniform grain structure, an absence of porosity and the specimen surface was polished. Therefore multiple tests on this sample configuration were used to determine the standard deviation of the stress to be within $\pm 7 \mathrm{MPa}$ and of the Young's modulus to be within $\pm 10 \mathrm{GPa}$.

\subsection{Analytical Techniques}

Cross sectional sample preparation for microscopy and electron backscatter diffraction (EBSD) involved water-cooled grinding with a 4000 grit finish and a good polish using a water-based $40 \mathrm{~nm}$ Opus colloidical silica suspension supplied by MetPrep on a cloth, type OP-Nap (supplied by Struers). Etching to reveal the microstructure was performed on cross sectional samples, which were $0.25 \mu \mathrm{m}$ diamond polished on an Alpha cloth (supplied by MetPrep). The etchant was a solution consisting of $10 \mathrm{ml}$ nitric acid and $15 \mathrm{ml}$ hydrochloric acid $(\mathrm{HCl})$ in $30 \mathrm{ml}$ methanol, which was applied within $1 \mathrm{~h}$ of preparation, as the mixture is known to rapidly decompose. The revealed grain morphology was studied using a standard inverted optical microscope. A thermal field emission gun (FEG) scanning electron microscope (SEM), type JEOL JSM-7001F was used to image fracture surfaces from the trials and to examine the microstructure and to perform energy dispersive X-ray spectroscopy (EDS) analyses. The imaging modes used were secondary electron (SE) and backscattered electron (BSE) in compositional contrast. The FEGSEM incorporated an integrated EDS detector, type INCA x-act-51-ADD0001, from Oxford Instruments. Electron backscatter diffraction (EBSD) was performed on a FEI Helios Nanolab 600i instrument, which was equipped with an EDAX Pegasus integrated EDX-EBSD system.

For transmission electron microscopy (TEM) sample preparation, sections of the SLM builds were separated using a low speed saw and ground to a thickness between 100 to $200 \mu \mathrm{m} .3 \mathrm{~mm}$ discs were then mechanically punched out from the sheets and centrally thinned to a thickness $<50 \mu \mathrm{m}$ with a 4000 grit 
finish from both sides. For wall builds, thin foils were prepared from the zone as close to the centre of the structures as possible although constant stirring in the melt pool during processing probably lead to a homogeneous distribution of oxide particles or pre-states of those throughout the wall thickness. Both cutting and grinding were performed under constant water cooling. A twin jet electropolishing technique was applied using a StruersTenupol-3 system and a 10\% perchloric acid in methanol solution as electrolyte, having a temperature of $\sim-50^{\circ} \mathrm{C}$, to achieve electron transparency. The nanostructure of the samples was investigated using a JEOL 2100FCs TEM/STEM in bright field mode operating at $200 \mathrm{kV}$. The particle size distribution was acquired from a series of $2048 \times 2048$ pixel TEM bright field images in $20 \mathrm{k} \times$ magnification and 200+ particles per group with a diameter $>10 \mathrm{~nm}$ were analysed.

\section{Experimental results}

\subsection{Microstructural characterisation}

As shown in Fig. 5a, the grain structure viewed from the top of the SLM wall 1 appeared to be double crescent shaped, while the central line close to the scan line acted as an interface between them. The morphology of SLM wall 2 and SLM wall 3 was similar to SLM wall 1, however grains between both deposit tracks merged and recrystallized to form grains which spanned from one weld track to another. A small number of build defects were present in all wall builds in the form of small $(<\sim 20 \mu \mathrm{m})$ pores near the scan line, but other defects, such as cracks, inclusions or larger pores were not observed. When viewed from the side (Fig. 5b), columnar grains oriented along the SLM growth direction were observed, up to several $\mathrm{mm}$ in length for SLM wall 1, but these were shorter in case of the other, thicker wall structures, SLM wall 2 and SLM wall 3.

A similar grain morphology for the block builds was also apparent in the top and side views presented in Fig. $6 a$ and $6 b$, with a preferential grain orientation along the SLM build direction. Porosity up to $\sim 150$ 
$\mu \mathrm{m}$ in size, with internal $\mathrm{O}, \mathrm{Al}$ and $\mathrm{Y}$-rich nodules were present with a non-random distribution (Fig. 6c). Inclusions up to $\sim 50 \mu \mathrm{m}$ in diameter were also observed near the interface between two deposited weld tracks (Fig. 6d). EDS measurements revealed these inclusions were oxides of $\mathrm{Al}$ and $\mathrm{Al}+\mathrm{Y}$. The $\mathrm{Al} / \mathrm{Y}$ ratio was subject to variations, while the $\mathrm{O}$ content remained at a stable level near 60 at.\%. Current work suggests that such inclusions are remains of a scale incorporated into the build during SLM, rather than agglomerated ODS precipitates [33].

EBSD was conducted on an as-grown SLM wall 1 in two viewing orientations - from the wall top (Fig. 7a) and from the side (Fig. 7b). The study revealed an inner region with a strong [001] fibre texture along the growth direction. The grains in this region were separated by both high angle and low angle grain boundaries and the average cross sectional area was $1940 \mu \mathrm{m}^{2}$ when viewed from the top. The grains in the outer zone with an average cross sectional area of $450 \mu \mathrm{m}^{2}$ were randomly oriented and merged typically with high angle grain boundaries. In order to improve statistical reliability, the average cross sectional area of the grains and the aspect ratio in side view was determined from micrographs in lower magnification; numbers obtained were $6320 \mu \mathrm{m}^{2}$ and 10.8 along the SLM build direction, respectively. The grain morphology of PM2000 fabricated by a conventional route has been studied extensively, for example by Klimiankou et al.[42]. In the as-extruded condition, this material showed micron-size grains elongated along the extrusion direction. The sheet taken from the as-extruded state in the present experiment was annealed for $1 \mathrm{~h}$ at $1380^{\circ} \mathrm{C}$, which resulted in a significantly coarsened grain structure. Grains were elongated along the extrusion direction over the sample length having widths up to several $\mathrm{cm}$. Thus, tensile specimens were machined typically from one single grain.

Investigation of TEM thin foil samples taken from the SLM builds revealed in all cases a fine homogeneous distribution of ODS particles. An example taken from SLM wall 1, in the as-grown condition is presented in Fig. 8a. Particulates were homogeneously dispersed in all builds, and the precipitate distribution seemed not to be increased on grain boundaries (Fig. 8b).

The oxide particle size distribution of samples taken from the SLM builds was compared with that of conventionally processed recrystallized PM2000 (Fig. 9). Particles less than $10 \mathrm{~nm}$ in diameter were 
present in low numbers and could not be analysed easily due to contrast issues as a result of large numbers of dislocations in the samples. The sample taken from SLM wall 1 showed a diameter size distribution with a main peak at $\sim 25 \mathrm{~nm}$ compared with a main peak at $\sim 30 \mathrm{~nm}$ for the extruded and recrystallized PM2000. SLM wall 3 had finer dispersoids with a main peak at $\sim 17 \mathrm{~nm}$. Particle diameters in the block builds were much greater than the wall structures with a main peak between 30 and $35 \mathrm{~nm}$ and a high number density of precipitates up to a particle diameter of $\sim 60 \mathrm{~nm}$.

\subsection{Analysis of YS, UTS and total elongation}

Fig. 10a,b presents key types of stress-strain curves observed and those specimens will be investigated in terms of fracture surface and cross section later in detail. Specimen configurations are summarised in Table 2 and it should be noted that un-recrystallized as-extruded material (ExBZAse) exhibited a significantly high UTS and rupture could not be achieved since the force required was above the limit of the test equipment. The rupture behaviour of walls along the growth direction $(\mathrm{Z})$ was ductile whereas, when tested perpendicular (X), it was predominantly brittle. As evident from Fig. 10c, this led to a higher total elongation of as-grown specimens of this build configuration in $\mathrm{Z}$ in the range of $\sim 7-11 \%$, whereas in $\mathrm{X}$ the values were in the range of $\sim 2 \%$. The heat treatment decreased the total elongation in $\mathrm{Z}$ direction typically slightly (from $\sim 10$ to $\sim 7 \%$ in the example displayed, SLM wall 1), whereas in X it remained virtually unchanged. However, values obtained for the total elongation should only be considered as a preliminary suggestion due to issues associated with miniaturised testing and work on significantly larger specimens should be used to investigate this property in detail [43]. For recrystallized extruded material tested in both directions, the individual values exhibited a great variance, which were obviously related to a very low number, typically 1 , of grains in the gauge section and therefore a strong effect of anisotropy. The total elongation of solid blocks was low in both test directions, which seems to be related to a high level of porosity since the total elongation is sensitive for this property. The test displayed (BkXAsG) 
exhibited a total elongation of $2.5 \%$ and values in that range were typical for all test orientations of this build configuration. Fig. 10d compares individual values of the YS and UTS and it was found that the alloy hardening was quite limited with ratio of both properties being relatively constant throughout the test series for all SLM builds with an average value of 0.88 in $\mathrm{Z}$ and 0.92 in $\mathrm{X}$.

\subsection{Detailed analysis of individual YS values}

The YS determined from the stress-strain plots of each build are summarised in Fig. 11 and the main observations are highlighted in colour. Changes in orientation of the test specimens from $\mathrm{Z}$ to $\mathrm{X}$ resulted in a slight increase of YS of about $53 \pm 4 \mathrm{MPa}$. This compares well with a small increase in YS, of about $57 \pm 7 \mathrm{MPa}$, which was observed for as-extruded reference material tested along and perpendicular to the extrusion direction, respectively. Application of a post-build anneal (heat treatment) also contributed to an increase in YS (dotted arrows) of wall structures, while the effect was strongest for SLM wall 1. The YS of annealed SLM build walls were promising with values approaching those of the conventional recrystallized PM2000. The recrystallization treatment on as-extruded reference material resulted in a strong decrease in YS, which is a well known effect [7], to average values of approximately $500 \mathrm{MPa}$ for both trial orientations (dashed arrows). The value was circa $100 \mathrm{MPa}$ below the data given in the literature [7] for this material, which may have only include one or two grains within the gauge length. Due to the existence of build defects (non-randomly distributed pores and inclusions), block builds were used only to demonstrate that YS up to approximately $520 \mathrm{MPa}$ and $500 \mathrm{MPa}$ can be achieved when tested along and perpendicular to the SLM growth direction, respectively (dashed boxes).

\subsection{Young's modulus}


The values of Young's modulus were determined from tests which were acquired with a high number of data points of the individual un-/re-loading sequences in order to improve the statistical reliability of the analysis. Typical values are displayed in Fig. 12. Wall builds tested in the $\mathrm{X}$ direction returned moduli in the range of $\sim 180-210 \mathrm{GPa}$. A change in the test orientation to $\mathrm{Z}$ resulted in $\sim 30 \mathrm{GPa}$ lower values. Another finding was that Young's moduli did not appear to be sensitive to wall thickness or annealing treatment. Young's moduli determined for specimens taken from PM2000 reference material showed, in a similar way, that the values in the extrusion direction were $\sim 25 \mathrm{GPa}$ lower than perpendicular to it, while the average values were $\sim 12$ GPa greater than those measured in the wall builds.

\subsection{Tensile behaviour and fracture morphology}

The fracture surfaces of failed key test specimens are displayed in Figs. 13 and 14. Fig. 15 shows the etched cross sections in low (optical) and higher (SE) magnification; the stress-strain plots of those are shown in Fig. 10.

The fracture surfaces of as-grown (W2XAsG) and annealed (W3XAnn) wall builds, tested perpendicular to the grain orientation (X), did not differ significantly and showed in both cases a brittle fracture parallel to elongated grain boundaries without significant necking. When testing wall builds along the orientation of the columnar grains (Z), ductile fracture was observed (W1ZAsG, W1ZAnn). Specimens sectioned from as-grown SLM wall 1, tested in the Z (W1ZAsG) direction, exhibited greater ductility during necking, hence higher strain-to-rupture than thicker and annealed walls in this test direction (W1ZAnn). Nanoscaled dimples were apparent on the fracture surface of this condition (W1ZAsG) (Fig. 13e) and ODS particles were located in the individual dimple centres as marked with arrows in Fig. 13f. On the other hand, thicker and annealed specimens in this test direction showed changes in the fracture morphology, and the volume fraction of areas showing dimples decreased with increasing heat input during fabrication (thicker walls) and post-build annealing. The annealed condition (W1ZAnn) appeared 
to be the most advanced state of this observation and nanoscopic dimples could no longer be observed, but a variety of other ductile fracture surface types were present instead (Fig. 13k-n). A common feature of all wall configurations tested in the $\mathrm{Z}$ direction was, metallurgical slip induced, grain deformation near the fracture surface as viewed in cross section in Fig. 15b,d. No build defects were observed in fracture surfaces of tested wall builds. This suggests those were not acting as weak points in the configuration, and hence are not significantly detrimental to tensile behaviour. As mentioned before, the measured YS was typically higher for walls tested along the $\mathrm{X}$ direction and those with increased wall thickness and subject to post-build annealing.

The morphology of the fracture surfaces of solid blocks showed a similar behaviour. However, as shown in Figure 14a-d, both brittle and ductile fracture could often be observed in one sample. This is probably associated with a more random grain orientation and anisotropy of the individual grains might promote a more brittle or ductile behaviour in certain regions. The area fraction of brittle fracture versus a ductile fracture surface showing dimples was increased for specimens tested in X compared to those tested in the $\mathrm{Z}$ direction suggesting that a certain fraction of the grains is fibre textured in a [001] orientation as was shown for SLM wall 1. The observed nanoscopic dimples in this configuration (BkXAsG), were larger in size than those observed on tested as-grown walls (W1ZAsG), but once again there were often ODS particles in the individual centres, see Figure 14d. In contrast to tested annealed wall builds, such dimples remained apparent in annealed block builds. However, a large number of build defects, including porosity and inclusions were observed in the fracture surfaces of annealed block builds; these were also evident when viewed in cross section. An example of a fractured block, in the as-grown condition, tested in the $\mathrm{X}$ direction, is displayed in Figure 14a and Figure 15e.

Recrystallized extruded material (ExBZRe) fractured in the $\mathrm{Z}$ direction with necking and the fracture surface was of a brittle type with a similar appearance to as-grown and annealed walls tested in the $\mathrm{X}$ direction (W2XAsG, W3XAnn). 


\section{Discussion}

\subsection{Micro and nanostructure}

The grain shape viewed from the top of the build was typical of SLM processes and is influenced by the geometry of the melt pool as heat flow and grain growth occurs perpendicular to the liquidus/solidus interface leading to the morphology observed [44]. In contrast to castings, where the solidification process is characterised by nucleation and grain growth, directional solidification processes, for instance of $\mathrm{Al}, \mathrm{Ni}$ and Fe-base alloys, are known to form elongated grain structures oriented along the [001] direction grown epitaxially from grains formed during deposition of the previous layer [30,45,46]. As shown in [47], both as-grown solids and wall builds do not recrystallize when conducting a standard recrystallization treatment of conventional PM2000 at $1380^{\circ} \mathrm{C}$ for $1 \mathrm{~h}$. This indicates that the initial grain size is too large and the stored energy is insufficient to trigger recrystallization, due to the multi-pass nature of deposition resulting in recovery during SLM growth which suppresses recrystallization.

Minor porosity observed along the laser scan line is probably associated with shrinkage due to the directional liquidus/solidus transition finishing near the centre of the walls, gas inclusions or keyhole formation, since it often appears at the former scan line.

The manufacturing parameters for laser hatch lines for walls and solid structures were similar. The overall heat input for block builds was significantly greater than wall builds due to the large number of successive weld tracks deposited. As was indicated in [33], depending on the density, fragments of oxide scale agglomerates, float on the melt pool and become integrated into the build, forming the observed inclusions. A relatively constant value of 60 at. $\% \mathrm{O}$ was measured in many of the inclusions and varying levels of $\mathrm{Al}$ and $\mathrm{Y}$ suggest that multiple phases coexist. All stable phases included in the $\mathrm{Al}_{2} \mathrm{O}_{3}-\mathrm{Y}_{2} \mathrm{O}_{3}$ phase equilibrium diagram contain 60 at. $\% \mathrm{O}$.

A fine and homogeneous ODS particle distribution in the SLM builds suggest at least some nucleation and growth occurs in the solidified matrix after deposition during the repeated heating cycles induced by 
the SLM process. Dispersoids in liquid metal would float and agglomerate, driven by density differences since the density of common Al-Y oxides is much lower than PM2000 and the liquidus temperature of these oxides is significantly higher than that of PM2000.

The observations on the particle size distribution of different builds can be explained as follows. Y diffuses slowly in the $\alpha$-Fe matrix with a diffusion coefficient of five orders of magnitude less at $1200^{\circ} \mathrm{C}$ compared to Ti in Fe [48], This would retard diffusion of $\mathrm{Y}$ into secondary phases. Thus, a certain amount of Y appears to be still in atomic supersaturated solution for SLM wall 1, which represents the build configuration subject to the lowest heat input for the fabricated builds. Due to the multipass nature of the thick wall and block build configurations, these specimens were subject to an increased number of repeated heating cycles, which facilitated nucleation and growth of fine precipitates and the coarsening of pre-existing oxides due to Ostwald ripening. The solid structures represent an advanced state of this mechanism as the heat input is highest, hence, the source of atomic Y for nucleation becomes exhausted and all precipitates were subject to coarsening.

\subsection{The effect of the micro and nanostructure on tensile behaviour and Young's modulus}

The investigations demonstrated that in all cases transgranular fracture mechanisms were apparent in the wall builds which were studied in more detail, since a stronger level of build defects in block builds has degraded their mechanical properties as evident from analyses of the YS and the total elongation. Minor porosity in the wall builds was not observed in the fracture surfaces, hence minor porosity does not appear to be detrimental, at least at room temperature.

PM2000 has a ferritic (body centred cubic) structure and cubic crystals are known to exhibit anisotropic mechanical properties for both tensile and elastic behaviour. The origin for this effect is different interatomic distances on certain planes during elastic deformation, while certain atomic slip planes are activated during plastic deformation. Consequently, increased average YS values of $~ 53 \mathrm{MPa}$, a brittle 
fracture behaviour and lower total elongation when testing in the $\mathrm{X}$ direction can be explained by this anisotropy due to a strong [001] oriented fibre texture in the direction of SLM growth, while the radial orientation was random. This observation is consistent with results of tensile testing of Ni-base solid SLM builds in different test orientations where the growth direction exhibited lower YS values compared to the perpendicular direction [49]. Observations in the present work suggest also that changes in the precipitate size distribution and probably the particle volume fraction have a strong effect on YS/UTS, the total elongation and the Young's modulus. The increase in YS after annealing, was more significant for the thinnest walls, SLM wall 1. This might be associated with the formation of a fine dispersion of ODS particles from the remaining Y, which is still in atomic supersaturated solution in the as-grown state. Due to an increased level of heat input during manufacturing, the level of $\mathrm{Y}$ in atomic solution in thicker asgrown wall builds is likely to be lower, as is the increase in YS during annealing. A higher number of fine dispersoids would pin dislocation movement to a larger extent, hence, increasing YS. Annealing (post build or during deposition) is also known to change the particle morphology from multiphase particles into predominantly single phase Al-Y oxides as was shown in previous studies [33], which changes coherency relationships and perhaps manipulates pinning efficiency. During tensile testing of specimens taken from an as-grown SLM wall 1 along the growth direction, the lower number of relatively coarse precipitates resulted in pile-up of dislocations around ODS particles and localised stress-concentration lead successively to rupture and the formation of the observed nanoscaled dimples. The enhanced pinning efficiency of dislocations for thicker and annealed walls tested in the same direction obviously altered the morphology of the fracture surface and besides increases in YS it also decreased the observed ductility and increased slightly the total elongation. For single crystal iron at room temperature, anisotropy leads to Young's moduli $\mathrm{E}_{[001]}$ (weakest) of $130 \mathrm{GPa}$ and $\mathrm{E}_{[111]}$ (strongest) of $285 \mathrm{GPa}$ [50]. This is similar to those experimentally determined for conventionally drawn and recrystallized PM2000 bars oriented along a [001] and a [111] direction tested at room temperature where the Young's moduli were 147 GPa and 298 GPa respectively [52]. The values determined in this work were $\sim 30 \mathrm{GPa}$ lower when testing in the $\mathrm{Z}$ direction compared with the numbers for the $\mathrm{X}$ direction, which can be explained by this effect since the 
[001] orientation exhibits the lowest Young's moduli. Values of the total elongation for conventional PM2000 in the as-extruded and the recrystallized states obtained at room temperature using conventional test specimens are in the range of 12 and $17 \%$ [51], respectively, which are similar to the values determined for the walls tested in growth direction. On the other hand, significantly lower values perpendicular to this orientation are texture related.

Non-randomly distributed porosity in block builds is obviously the origin of failure of such structures as this reduces the effective cross sectional area in the gauge section. Also, due to their non-spherical shape, they would act as crack initiation points as shown on mechanically tested structures produced, for example, via Laser Beam Deposition (LBD) [53] resulting on the other hand in low values for the total elongation of the solid builds. Larger dimples in the fracture surface of both as-grown and annealed block builds suggest an absence of fine strengthening precipitates in both conditions. The occurrence of both brittle and ductile zones on fractured specimens taken from blocks can be attributed to a more randomly oriented grain structure.

For the extruded material, several mechanisms would explain a significant decrease in YS after the recrystallization treatment, such as particle coarsening, recovery mechanisms, a Hall-Petch relationship [14] and recrystallization induced porosity [54]. Obviously, most of the miniaturised test samples of the reference material were fabricated from one single grain and anisotropy explains changes in YS and Young's modulus depending on the test direction.

\subsection{Future work}

Further work is necessary to reduce porosity in solid builds and to refine precipitates and perhaps find methods to manipulate the grain structure. Increased density of SLM solid builds can typically be achieved by slower traverse speeds or higher laser power, however this would result in undesirable coarse ODS particles. Thus, process parameter and ODS alloy development should be conducted in parallel. 
Another route might exploit hot isostatic pressing of SLM builds to reduce porosity. Additions of certain elements, such as group 4 elements ( $\mathrm{Ti}, \mathrm{Zr}, \mathrm{Hf}$, etc.), are known to have a direct effect on the formation velocity of precipitates and other elements can increase fluidity of the melt pool, leading to potential advantages to fabricate dense solid builds with a reduced heat input with a fine ODS particle dispersion and/or with $\mathrm{Y}$ in atomic solution. A post-build annealing procedure might be developed to adjust particle size distribution for such novel build configurations. The fact that a strong fibre texture can be achieved for such SLM builds may be utilized to optimise mechanical properties in certain orientations, as it is the case for directionally solidified Ni-based superalloy used in turbine blades. Tensile, creep and oxidation testing of the present wall builds at elevated temperatures is a subject currently being considered. Other studies should cover further investigations on grain orientation (EBSD), dispersoid morphology, precipitate/matrix coherence relationships and the effect of annealing on such properties.

\section{Conclusions}

In this work, we examined the tensile response and fracture behaviour of SLM-ODS PM2000 solid structures and walls having different thicknesses using miniaturised tensile testing. The emphasis was placed on an investigation of SLM walls, since solid builds exhibited a strong non-randomly occurring porosity.

1) A post-build anneal resulted in an increase of the YS of wall builds up to values of conventionally fabricated recrystallized PM2000, which was less significant for thicker wall builds, which were grown with parallel hatch lines.

2) TEM work has shown that a fine dispersion of precipitates was retained in the as-grown SLM structures subject of this work. The findings on tensile response suggest that heating during postbuild annealing or by the deposition of parallel hatch lines led to the formation of new small 
precipitates by utilising certain amounts of $\mathrm{Y}$, which was still in solid solution in the as-grown state. This effect would enhance trapping efficiency of dislocations and consequently increase YS.

3) YS and Young's modulus exhibited anisotropic tendencies due to a strong [001] fibre texture and columnar grains along the SLM growth direction. Along this orientation, both properties were decreased and the behaviour was ductile, whereas when tested perpendicular to this direction, the specimens ruptured in an transgranular brittle manner.

\section{Acknowledgements}

The builds were produced in the Manufacturing Science and Engineering Research Centre at the University of Liverpool (UoL) led by Dr C.J. Sutcliffe and members of the group, in particular Dr J. Singh and Dr J. Robinson, gave valuable input. Thanks to Dr G. Pimentel from the Centro Nacional De Investigaciones Metalúrgicas in Madrid, Spain for providing a recipe of an etchant to reveal the grain structure of the present builds. We are grateful for financial support of the work through the Advanced Research Materials (ARM) Programme, U.S. Department of Energy, Office of Fossil Energy managed by U.T.-Battelle, LLC and funding by EPSRC grant EP/H018921/1 (Materials for Fusion and Fission Power).

\section{References}

[1] Ukai S, Fujiwara M. J Nucl Mater 2002;307-311:749.

[2] Quadakkers WJ. Werkst. Korros. 1990;41(12):659.

[3] Yu G, Nita N, Baluc N. Fus Eng Des 2005;75-79:1037.

[4] Simms NJ, Norton JF, McColvin G. Mat and Corr 2005;56(11):765. 
[5] Pint BA. Mater Sci Forum 2011;696:57.

[6] Capdevila C, Miller U, Jelenak H, Bhadeshia HKDH. Mater Sci Eng A 2001;A316:161.

[7] Plansee PM2000 alloy brochure, Plansee GmbH, Reutte, Austria.

[8] Yutani K, Kishimoto H, Kasada R, Kimura A. J Nucl Mater 2007;367-370:423.

[9] Kasada R, Takahashi H, Kishimoto H, Yutani K, Kimura A. Mater Sci Forum 2010;654656:2791.

[10] Ukai S, Okuda T, Fujiwara M, Kobayashi T, Mizuta S, Nakashima H. J Nucl Sci Tech 2002;39(8):872.

[11] Ukai S, Fujiwara M. J Nucl Mater 2002;307:749.

[12] Klueh RL, Shingledecker JP, Swindeman DT, Hoelzer DT. J Nucl Mat 2005;341:103.

[13] Schneibel JH, Heilmaier M, Blum W, Hasemann G, Shanmugasundaram T. Acta Mat 2011;59:1300.

[14] Kim JH, Byun TS, Hoelzer DT, Park CH, Yeom JT, Hong JK. Mater Sci Eng 2013;A559:111.

[15] Chou TS, Bhadeshia HKDH, McColvin G, Elliott IC. In: Proc. of the 2nd Int. Conf. on Structural Applications of Mechanical Alloying, ASM, Vancouver;1993:77.

[16] Williams CA, Unifantowicz P, Oksiuta Z, Baluc N, Smith GDW, Marquis EA. Mat Res S C 2011;1298:15.

[17] Molian PA, Yang YM, Patnaik PC. J Mater Sci 1992;27:2887.

[18] Chen CL, Wang P, Tatlock G.J. Mater High Temp 2009;26(3):299.

[19] Wang J, Yuan W, Mishra RS, Charit I. J Nucl Mater 2013;430:274.

[20] Sittel W, Basuki WW, Aktaa J. J Nucl Mater 2013;443:78.

[21] Noh S, Kasada N, Oono N, Iwata NY, Kimura A. Fusion Eng Des 2010;85:1033.

[22] Tatlock GJ, Dyadko EG, Dryepondt SN, Wright IG. Metall Mater Trans A 2007;38A:1663.

[23] Lindau R, Klimenkov M, Jäntsch U, Möslang A, Commin L. J Nucl Mater 2011;416:22.

[24] Kelly TJ. AIP Conference Proceedings 1979;50(1):215.

[25] Molian PA, Yang YM, Patnaik PC. J Mater Sci 1992;27:2887. 
[26] Lemmen HJK, Sudmeijer KJ, Richardson IM, van der Zwaag S. J Mater Sci 2007;42:5286.

[27] Walker JC, Berggreen KM, Jones AR, Sutcliffe CJ. Adv Eng Mater 2009;11(7):541.

[28] Suresh Kumar K. Procedia Mater Sci 2014;6:821.

[29] Hügel H, Graf T. Laser in der Fertigung (in German), second ed. Wiesbaden: Vieweg +Teubner; 2009.

[30] Thijs L, Kempen K, Kruth J-P, Van Humbeeck J. Acta Mater 2013;61:1809.

[31] Dahotre NB, Harimkar SP. Laser Fabrication and Machining of Materials, London et al., Springer; 2002.

[32] Boegelein T, Jones AR, Rao A, Tatlock GJ. ASME Pressure Vessels and Piping Division (Publication) 2011;6(A,B):19.

[33] Boegelein T, et al. "Characterisation of a complex thin walled structure fabricated by selective laser melting using a ferritic oxide dispersion strengthened steel" in preparation for Mater Charact, 2015.

[34] Ostwald W. Z Phys Chem 1901;37:385.

[35] Schaffer GB, Loretto MH, Smallman RE, Brooks JW. Acta Mat 1989;37(9):2551.

[36] Voorhees PW, Schaeffer RJ, Acta Metall 1987;35(2):307.

[37] Pandey A, Shyam A, Watkins T, Lara-Curzio E, Stafford R, Hemker K. J Am Ceram Soc 2014;in press.

[38] Benito JA, Jorba J, Manero JM, Roca. Metall Mater Trans A 2005;36(12):3317.

[39] Eberl C, Thompson R, Gianola D. Digital image correlation and tracking with Matlab. User guide. Published on Matlab Central file Exchange; 2006.

[40] Eberl C, Gianola DS, Hemker KJ. Exp Mech 2010;50(1):85.

[41] Pandey A, Tolpygo VK, Hemker KJ. JOM 2013;65:542.

[42] Klimiankou M, Lindau R, Möslang A, Schröder J. Powder Metall 2005;48(3):278.

[43] Kohyama A, Matsui H, Abe K, Hamada K, Asano K. J Nucl Mater 1988;155-157:1354.

[44] Antonysamy AA. Ph.D. Thesis, University of Manchester 2012.

[45] Gäumann M, Henry S, Cléton F, Wagnière J-D, Kurz W. Mater Sci Eng A 1999;A271:230. 
[46] Niendorf T, Leuders S, Riemer A, Richard H-A, Tröster T, Schwarze D. Metall Mater Trans B 2013;B44:794.

[47] Boegelein T. Ph.D. Thesis, University of Liverpool, in preparation, 2014.

[48] Hin C, Wirth BD, Neaton JB. Phys Rev B 2009;80(13):134118.

[49] Brodin H, Andersson O, Johansson S. In: Proc ASME Turbo Expo 2013, paper 101331.

[50] Courtney TH. Mechanical Behaviour of Materials, second ed. New York: McGraw-Hill; 2000.

[51] Rieken JR, Anderson IE, Kramer MJ, Dryepondt SN, Hoelzer DT. In: Proc TMS 2013.

[52] Herzog R. Ph.D. Thesis, Forschungszentrum Jülich, 1997.

[53] Amsterdam E, Kool GA. In: Proc ICAF 2009, p.1261.

[54] Chen YL, Jones AR. Metall Mater Trans A 2001;A30:2077. 


\section{Table captions}

Table 1. The elemental composition (wt.\%) of mechanically alloyed PM2000 according to the alloy datasheet [31] (A) and according to an analysis on the powder by ICP-OES (B).

Table 2. Description of key specimens investigated further. 


\section{Figure captions}

Fig. 1. The SLM operating principle. The image shows the scanner system (1) with a focussed laser beam (2), the powder container (3), the wiper \& powder deposition mechanism (4), a moveable arm (5), the gas nozzle system (6), the moveable piston (7), the substrate plate (8), the powder bed with a consolidated part (9) and a powder overflow (10).

Fig. 2. The walls and block structures fabricated by SLM.

Fig. 3. Optical micrographs of the utilized test specimen shown of the example of SLM wall 1 for testing perpendicular to the growth direction (X). Part (a) displays specimen dimensions of the as grown sample in $\mathrm{mm}$ and (b) shows the same piece conventionally mounted, prepared in cross section and etched to reveal the grain structure.

Fig. 4. Schematic of the direction of specimen cut out from SLM walls, SLM blocks and an extruded bar.

Fig. 5. Optical micrographs of etched cross sectional samples of the investigated SLM wall structures. Two viewing directions are displayed: from top of the build (a) and from the side (b) and exhibit a columnar grain orientation along the SLM growth direction.

Fig. 6. Cross sectional etched micrographs of the SLM block structure viewed in two different orientations. The images show (a) a stirred microstructure when viewed from the build top, (b) a stirred microstructure with grains oriented along the SLM growth direction when viewed from the side. Two types of build defects were revealed, which are (c) porosity and (d, e) inclusions consisting of oxides of $\mathrm{Al}$ and $\mathrm{Y}$. 
Fig. 7: Results of an EBSD scan of SLM wall 1 (as-grown) in the two viewing directions (a) from top of the build and (b) from the side of an approximate depth as marked (1). As marked (2), the scanning direction of one single pass per slice was from left to the right in the view displayed. Strongly evident is an inner zone with a strong [001] fibre texture (3) and an outer zone with more randomly oriented grains (4). (For interpretation of the references to colour in this figure, the reader is referred to the web version of this article.)

Fig. 8. TEM bright field images of a sample taken from SLM wall 1 (as-grown). A fine dispersion of nanoscopic precipitates was apparent (a), which were also occasionally located on grain boundaries (b).

Fig. 9. Dispersoid size distribution of thin foil samples taken from SLM builds, compared with extruded and recrystallized PM2000.

Fig. 10. Evaluation of characteristic stress-strain plots observed during the tensile experiments, which are plot in parts $(\mathrm{a}, \mathrm{b})$; the data are displayed up to a strain of $1.2 \%$. The individual total elongation of the tests is shown in (c) and the YS and UTS values in (d). In (a,b), the standard deviation is smaller than the size of the data points. Rupture of specimen ExBZAse could not be achieved.

Fig. 11. Diagram of the determined $0.2 \%$ offset yield stresses of the conducted microtensile experiments compared with data taken from literature [7]. The standard deviation is smaller than the size of the data points.

Fig. 12. Typical Young's moduli of key samples which were not subject to slip effects in the grips.

Fig. 13. Secondary electron images of characteristic fracture surfaces of the ruptured specimens in different levels of magnification. The individual parts show SLM wall 2, as grown, tested in the X 
direction (a-c); SLM wall 1, as grown, tested in the Z direction (d-f); SLM wall 3, annealed, tested in the $\mathrm{X}$ direction (g-i); SLM wall 1, annealed, tested in the Z direction (j-n). Arrows indicate ODS precipitates.

Fig. 14: Secondary electron images of characteristic fracture surfaces of the ruptured specimens in different levels of magnification. The individual parts show SLM block, as grown, tested in the X direction (a-c); Extruded bar, recrystallized, tested in the $\mathrm{Z}$ direction (e-g). Arrows indicate ODS precipitates.

Fig. 15: Optical images at low magnification and secondary electron images at higher magnification of the fractured region of key samples in cross section after etching. The individual parts show SLM wall 2, as grown, tested in the $\mathrm{X}$ direction (a); SLM wall 1, as grown, tested in the Z direction (b); SLM wall 3, annealed, tested in the X direction (c); SLM wall 1, annealed, tested in the Z direction (d); SLM block, as grown, tested in the $\mathrm{X}$ direction (e); extruded bar, recrystallized, tested in the $\mathrm{Z}$ direction (e). 


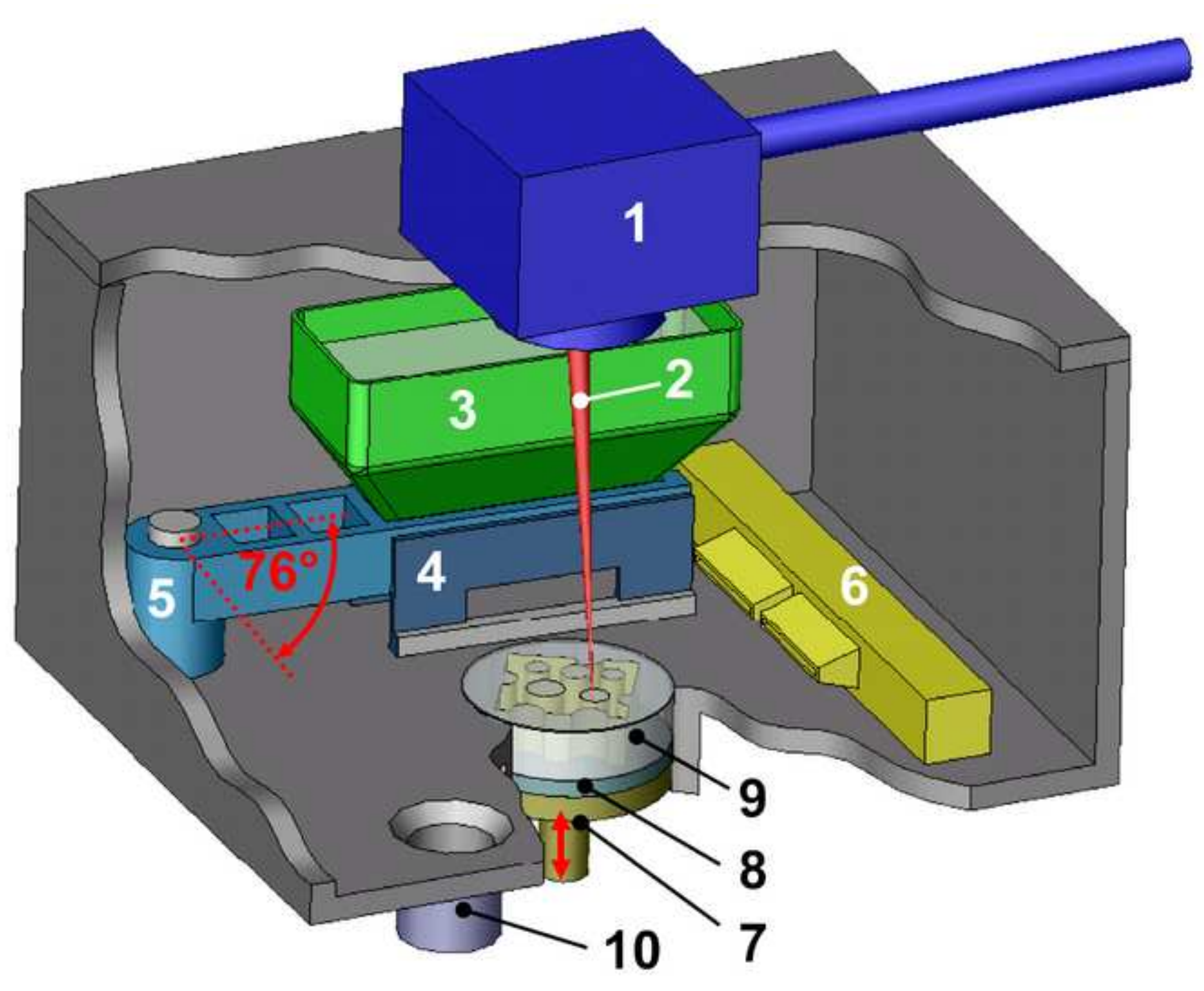



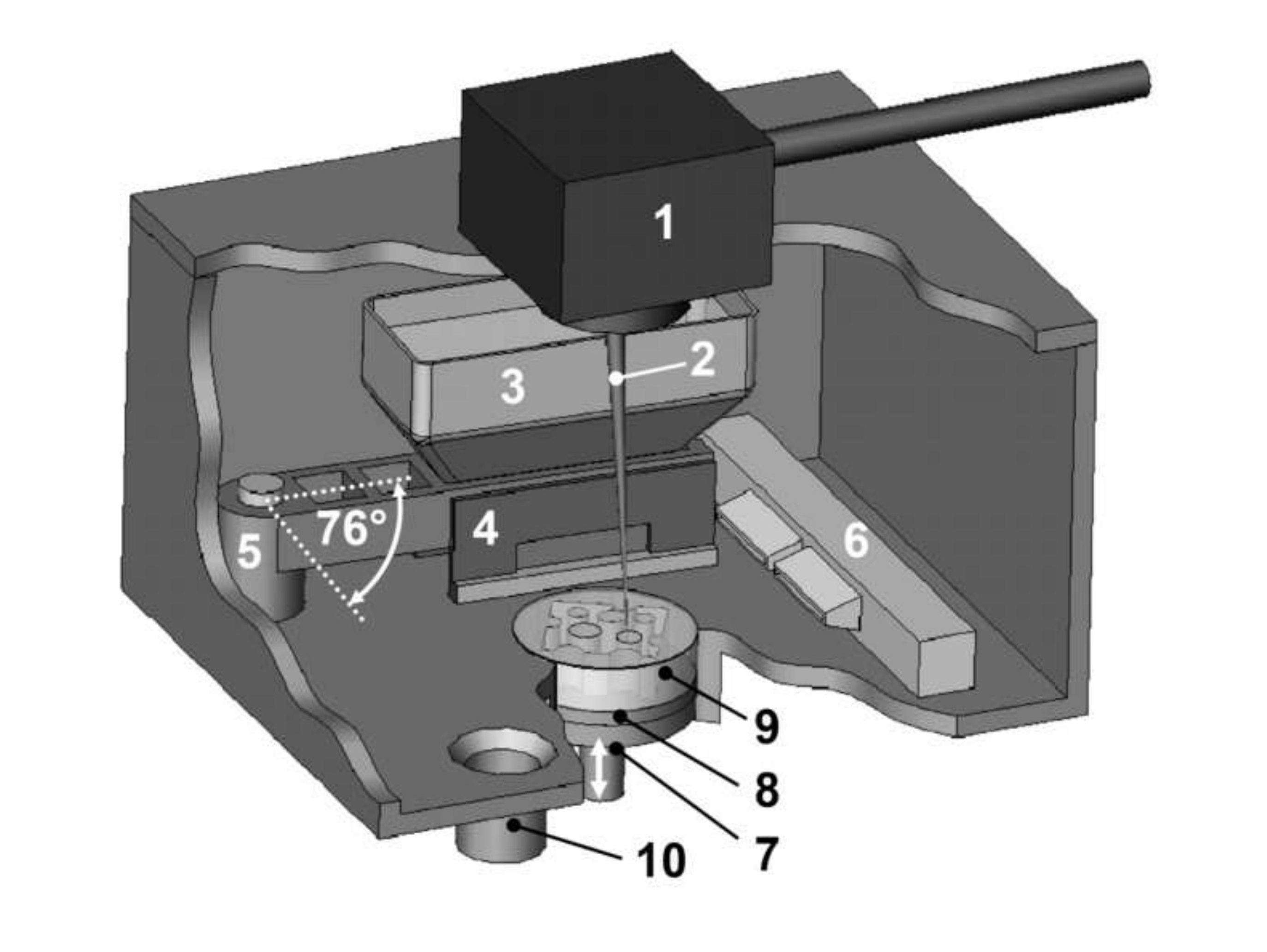

\section{Figure 1 (print version), single column}

.




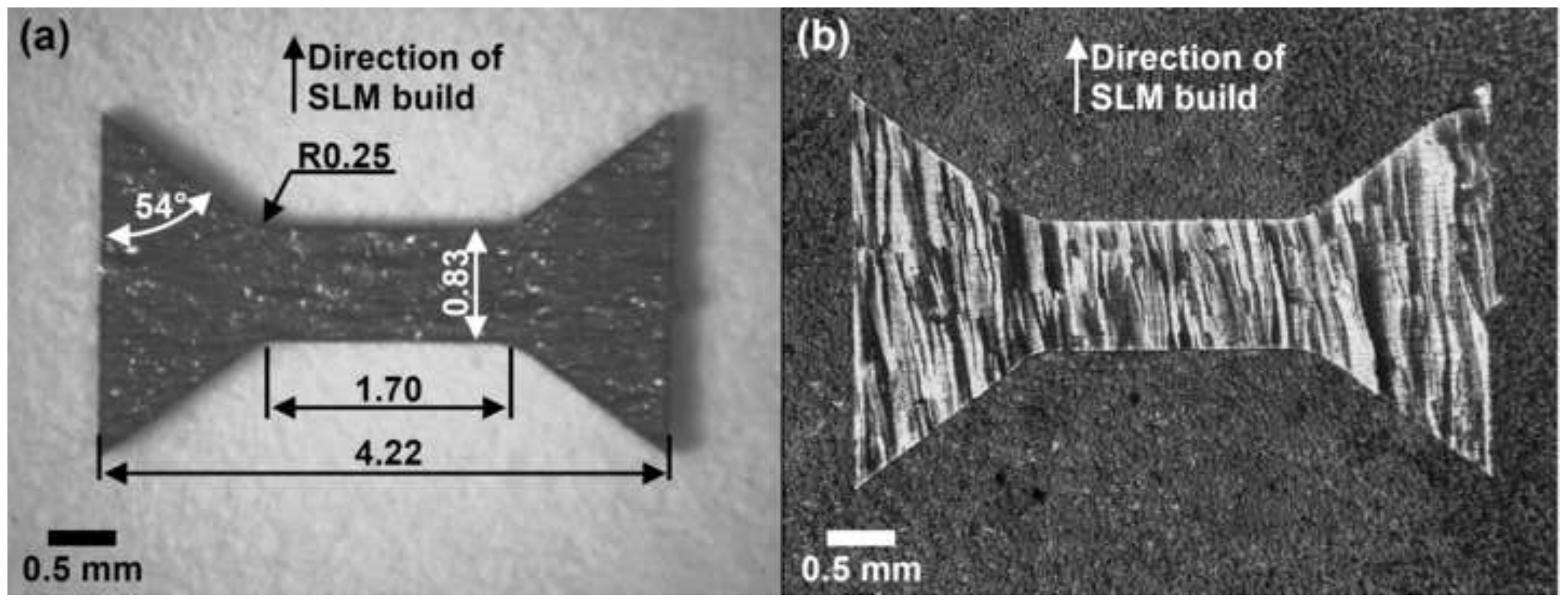


SLM walls

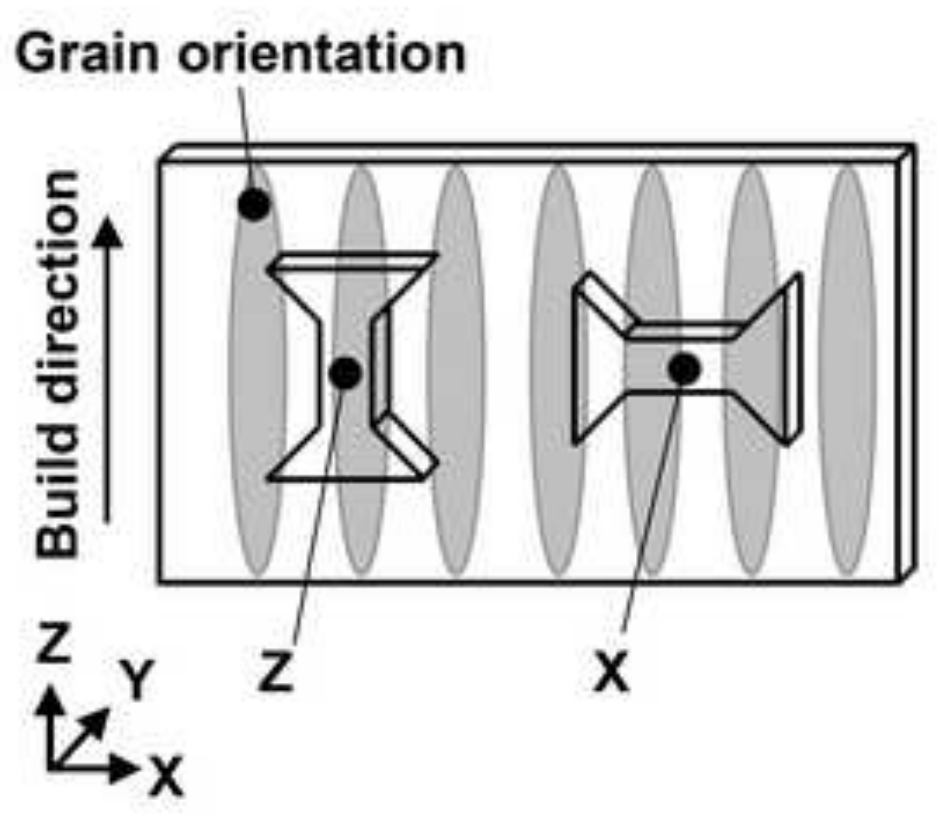

SLM block

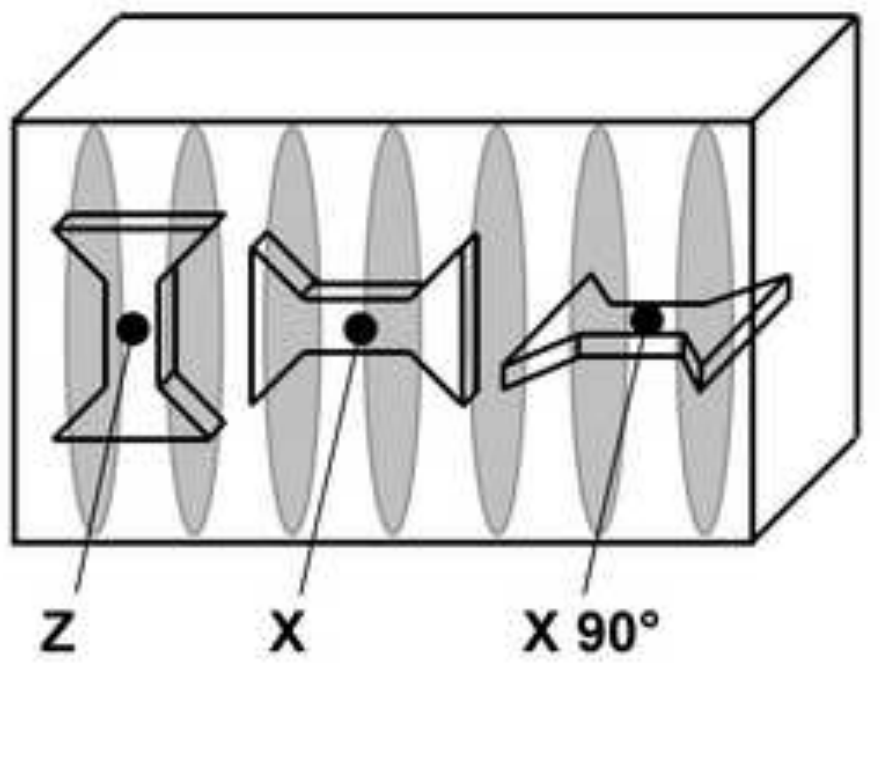

Sheet taken from extruded bar

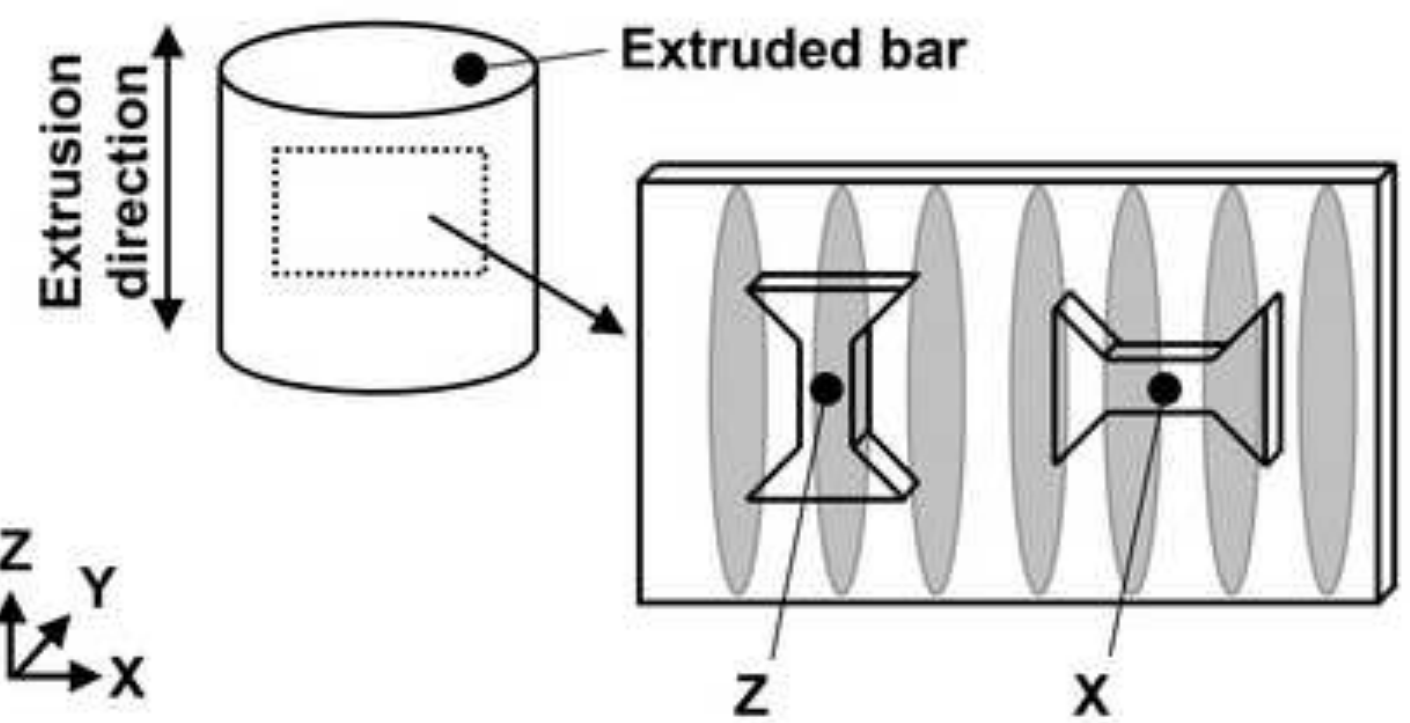



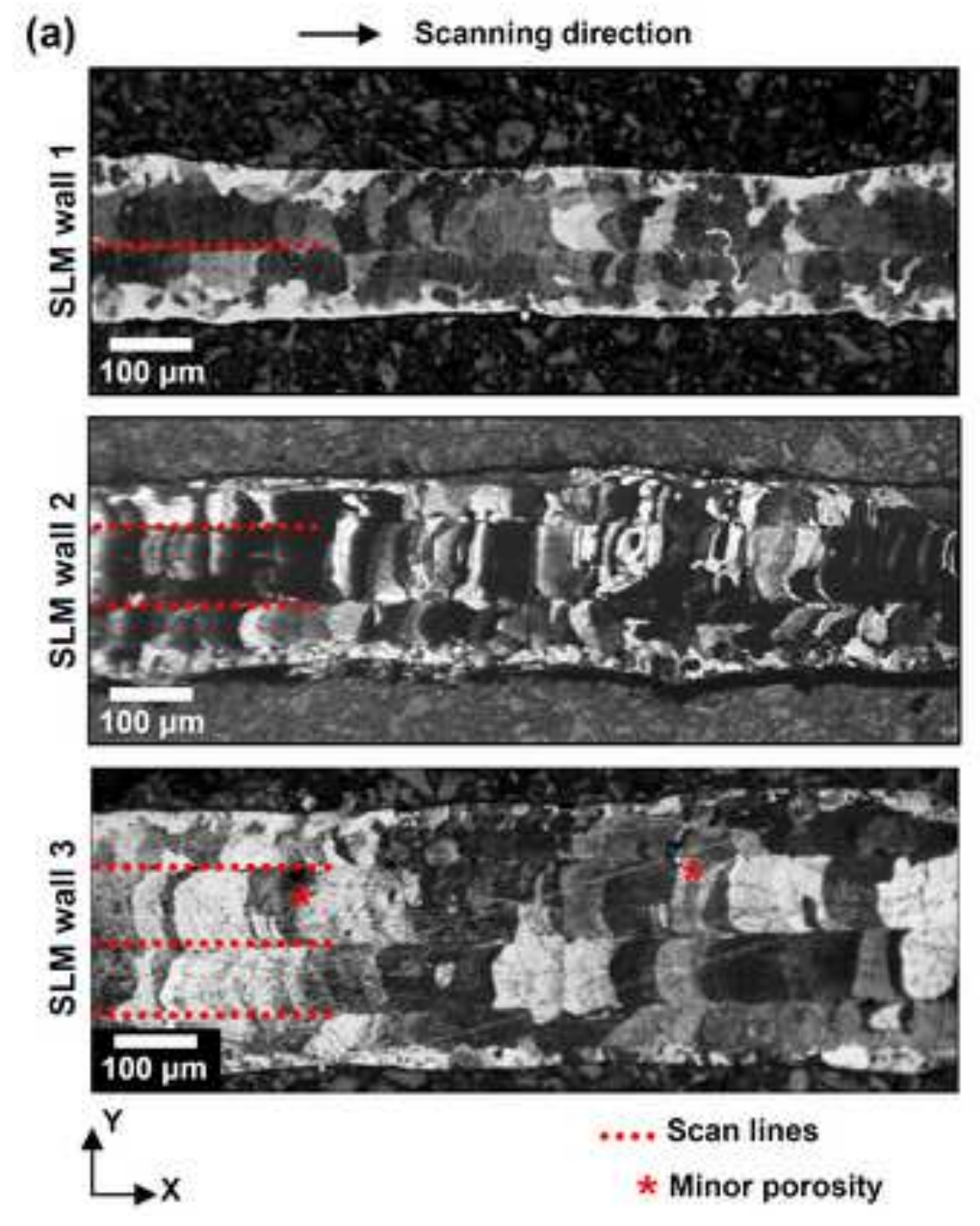

(b)

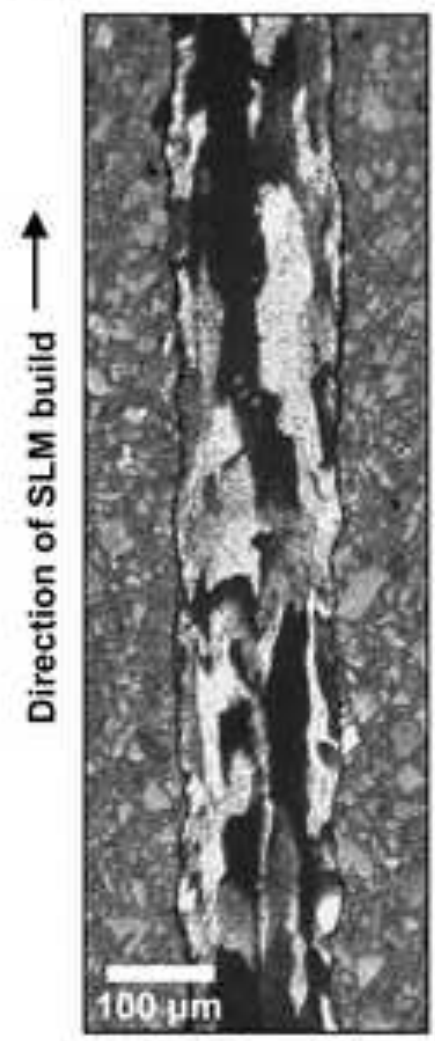

SLM wall 1

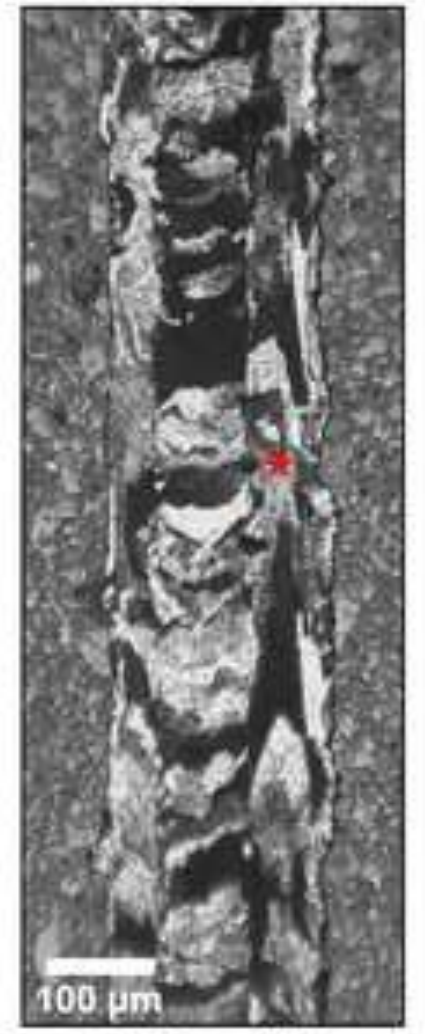

SLM wall 2

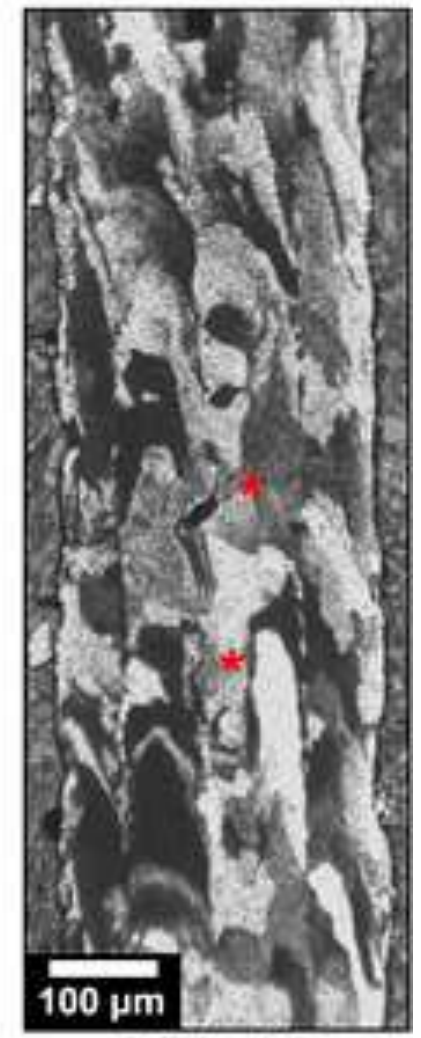

SLM wall 3

* Minor porosity 

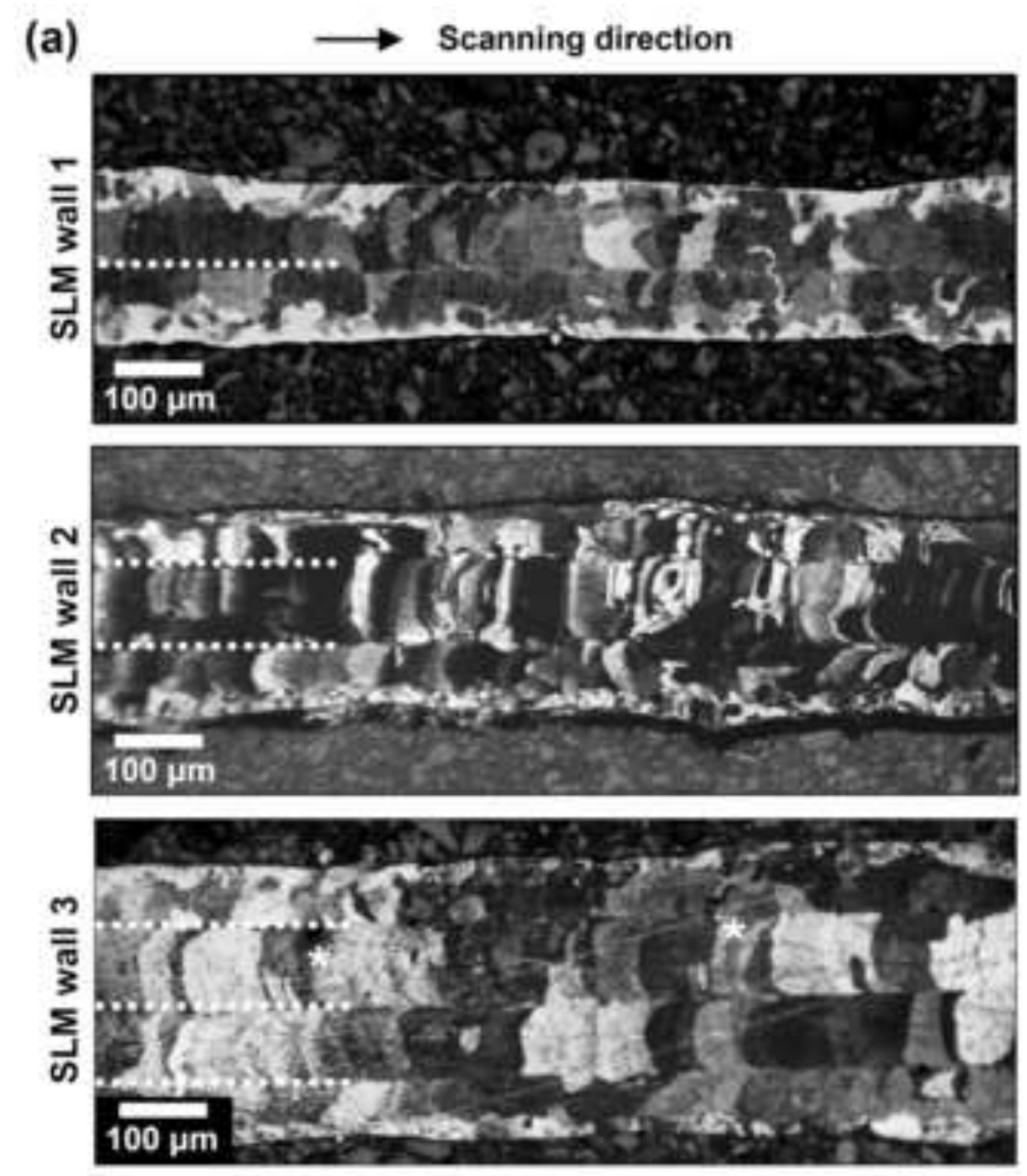

(b)
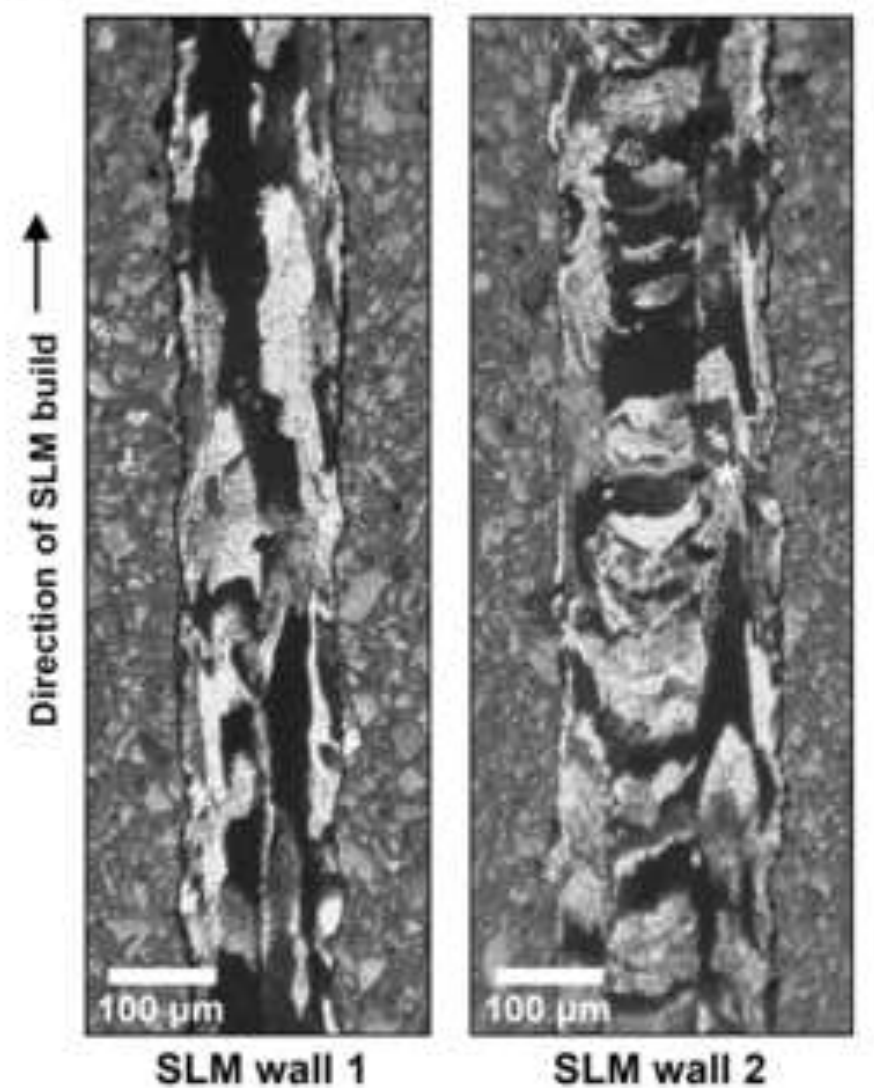

SLM wall 2
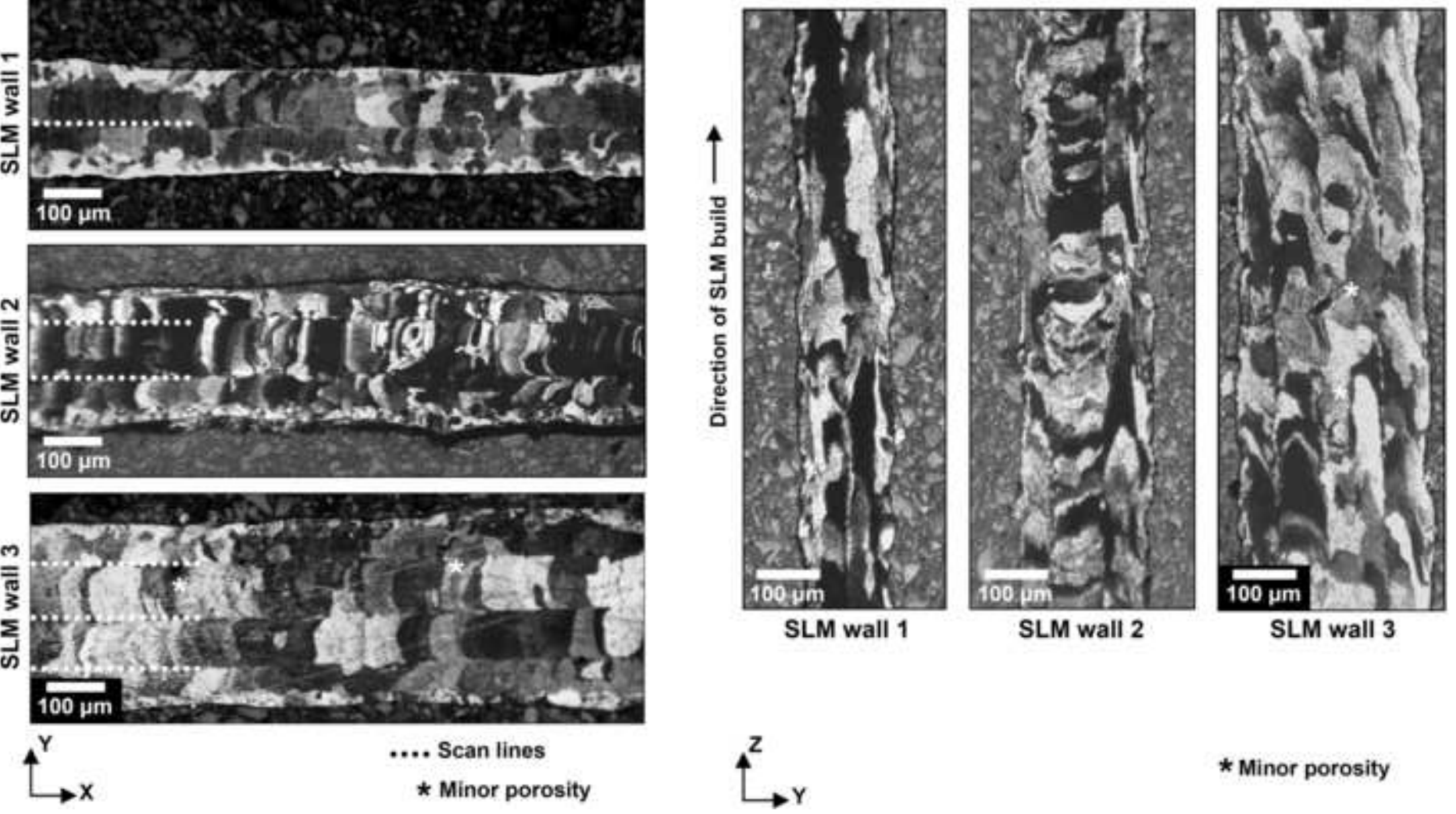

* Minor porosity 

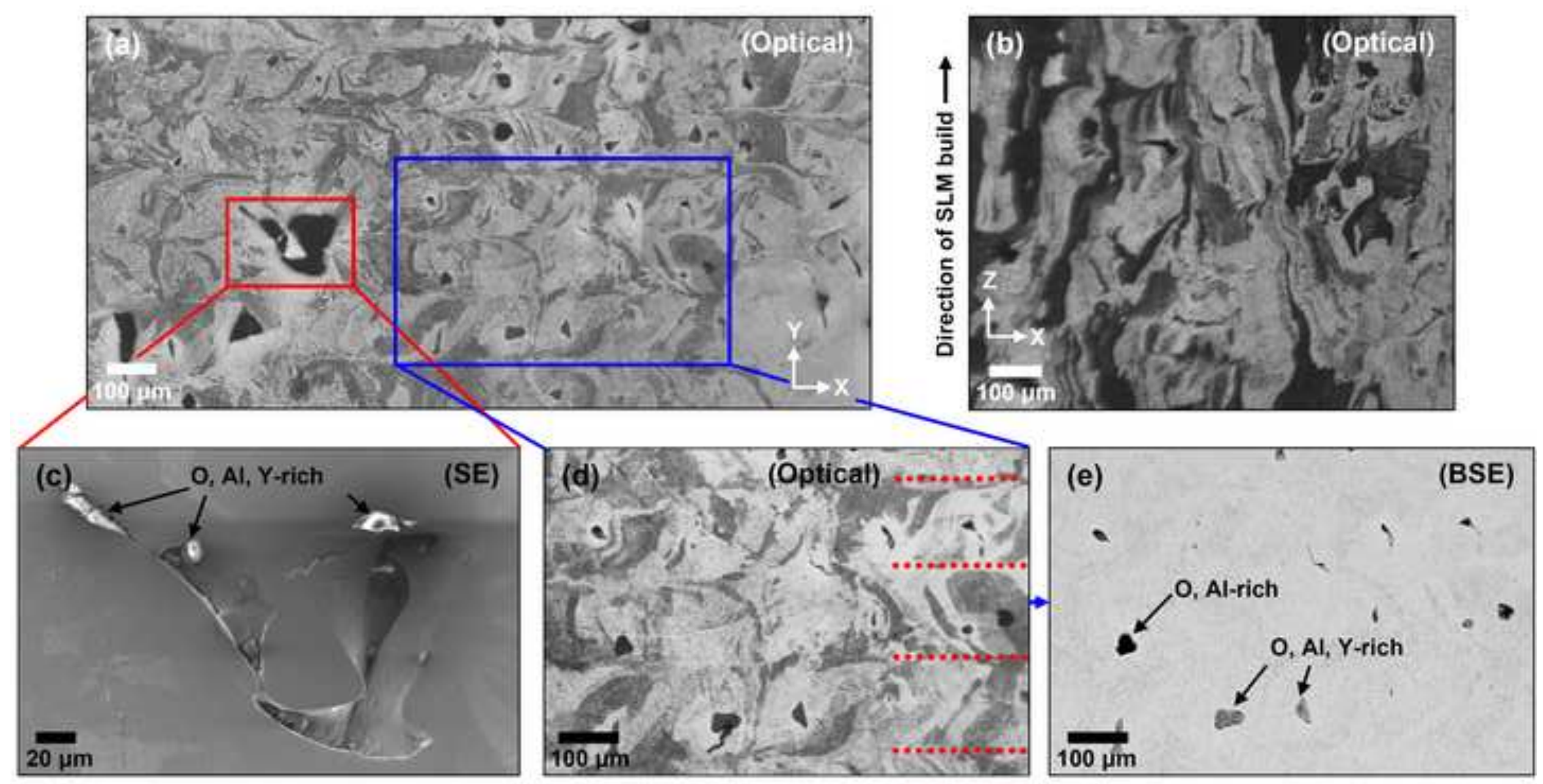

.... Scan lines of the slice viewed

$100 \mu \mathrm{m}$

( 

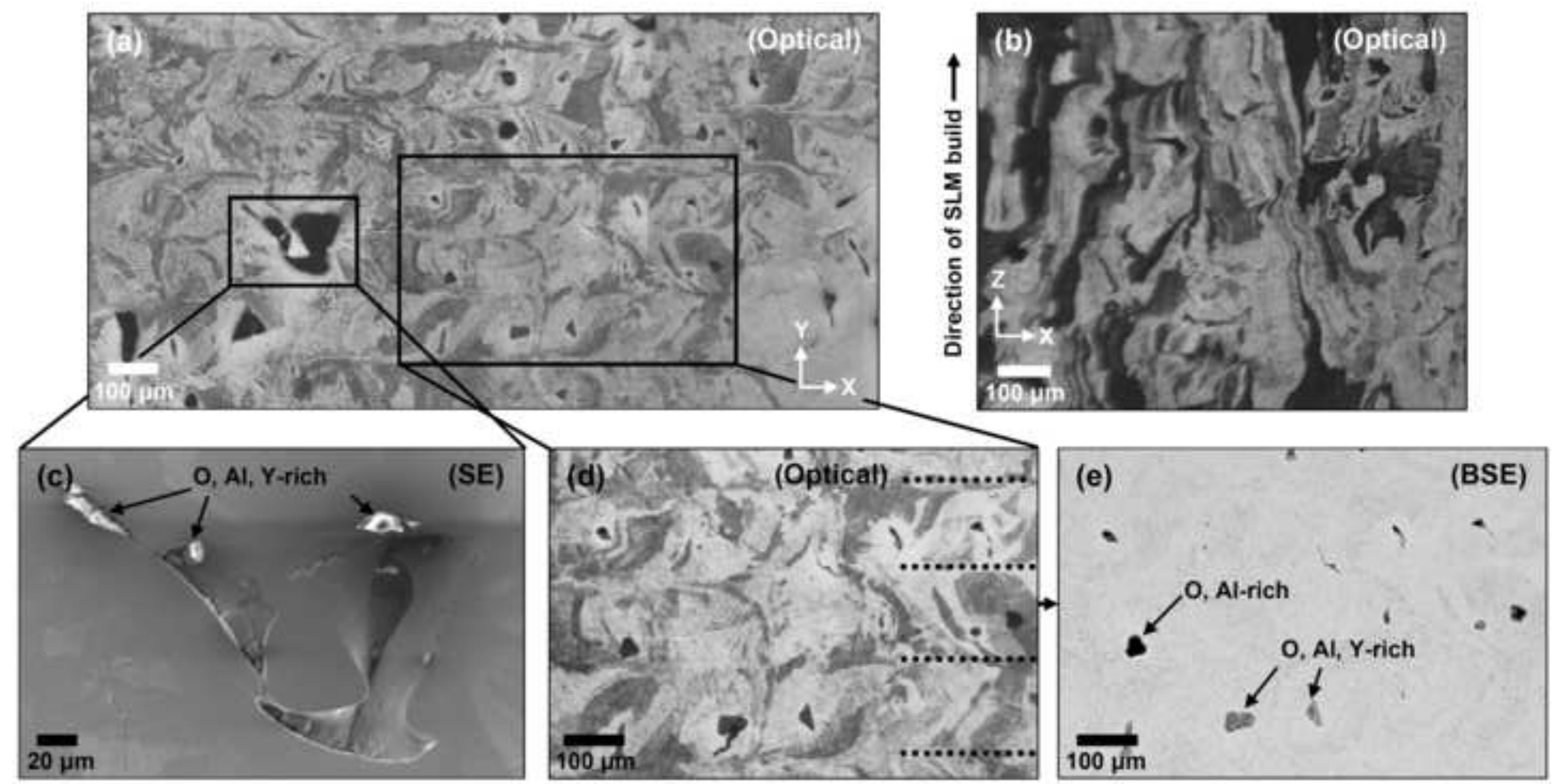

\section{.... Scan lines of the slice viewed}



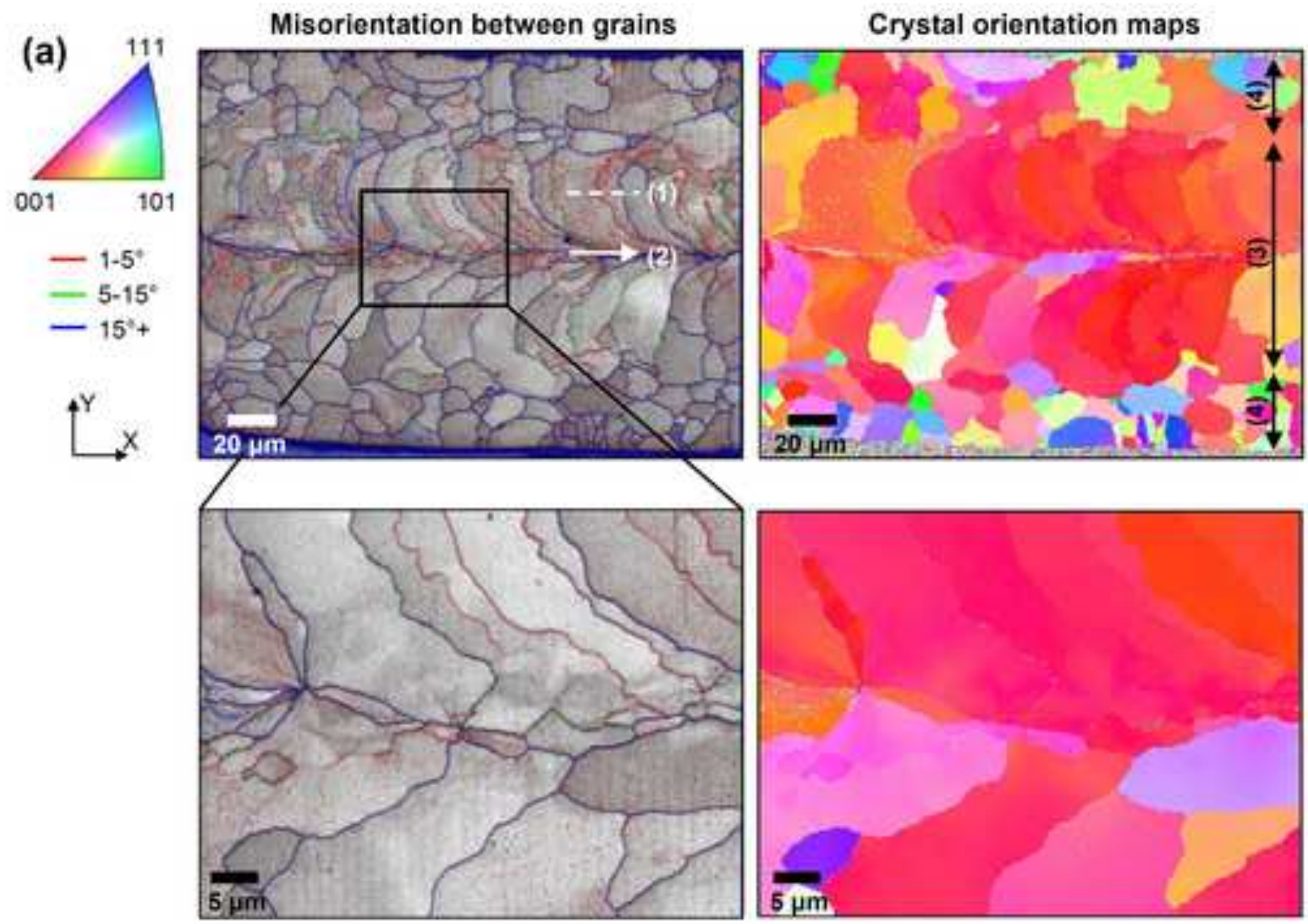

\section{Texture plots}
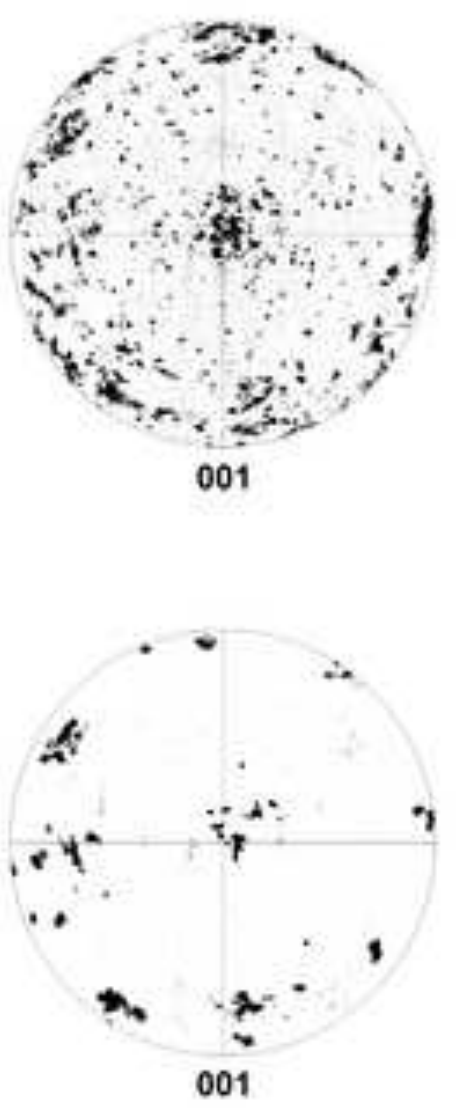

(b)
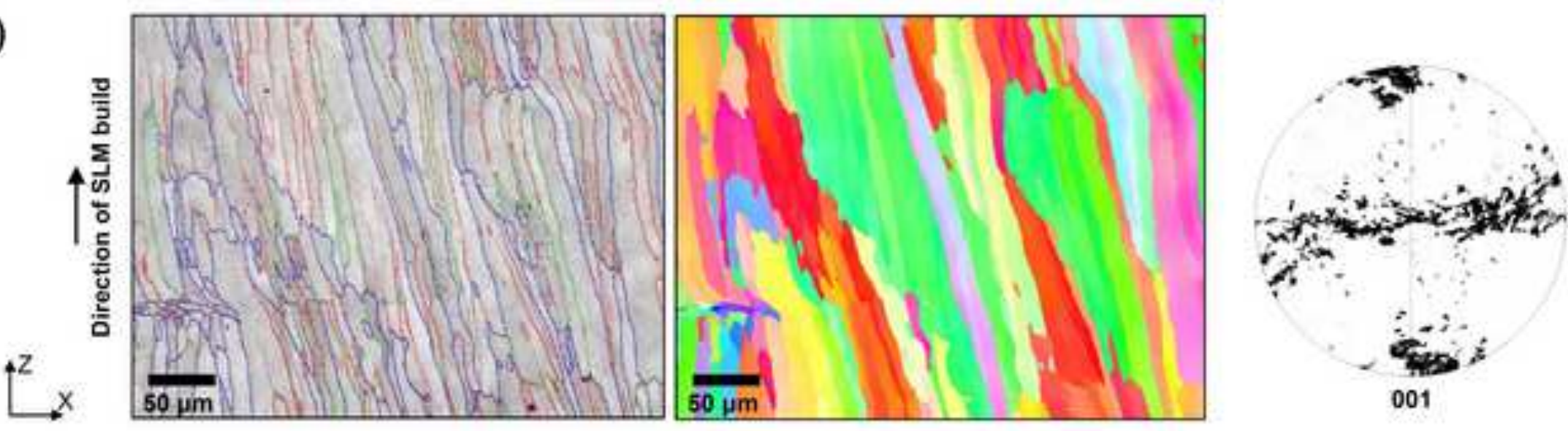
Figure 7 (print version), 2 columns
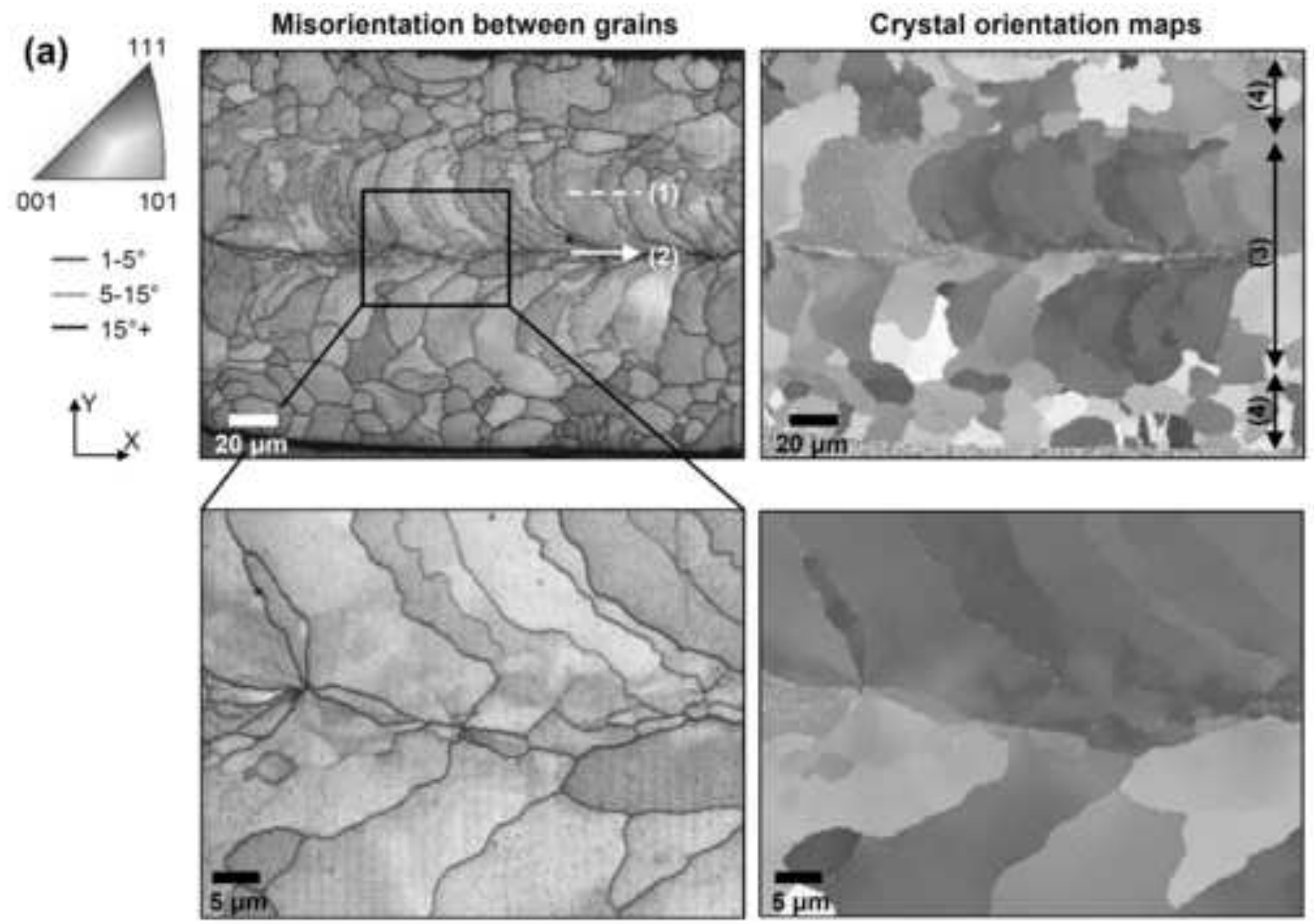

\section{Texture plots}
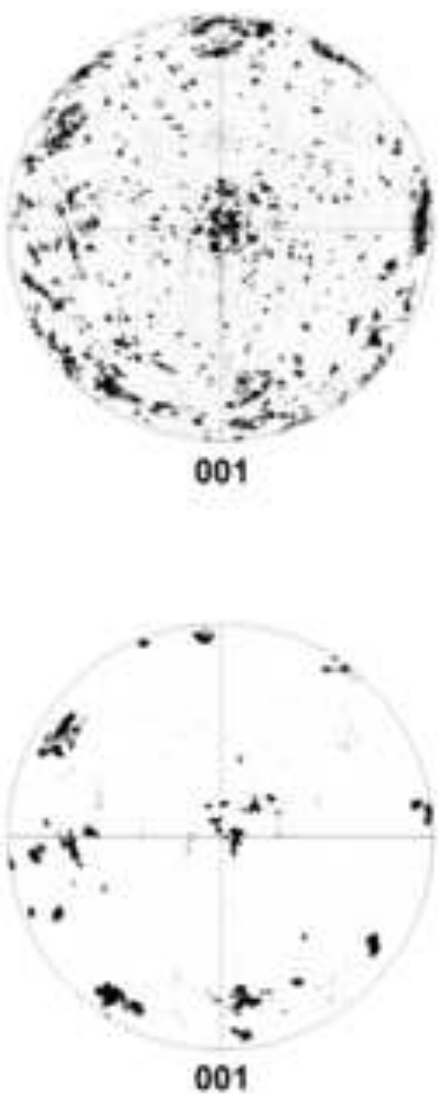

(b)
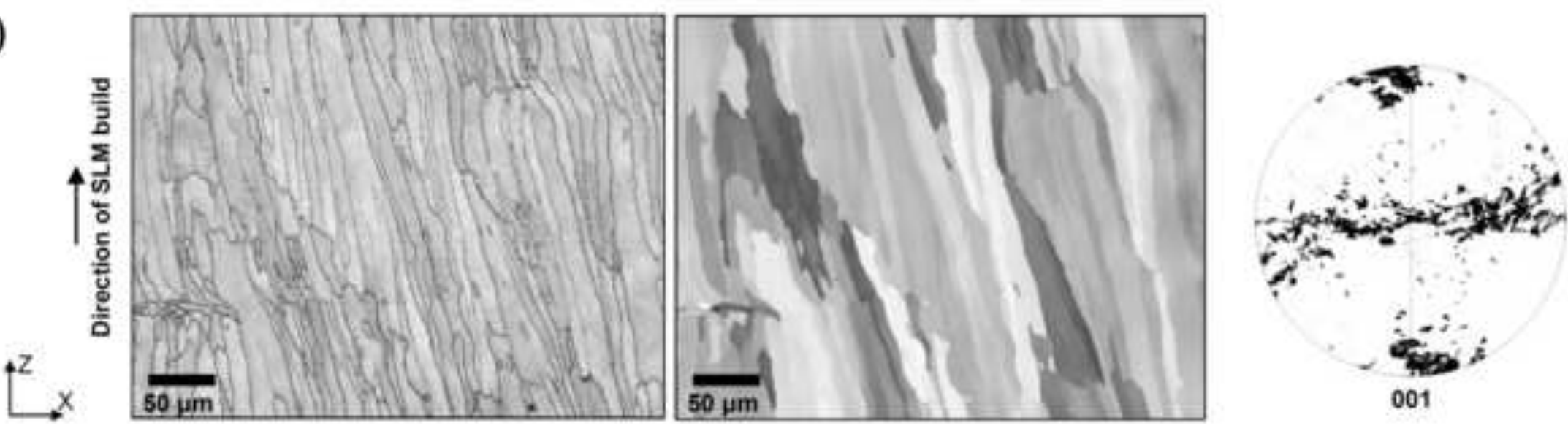


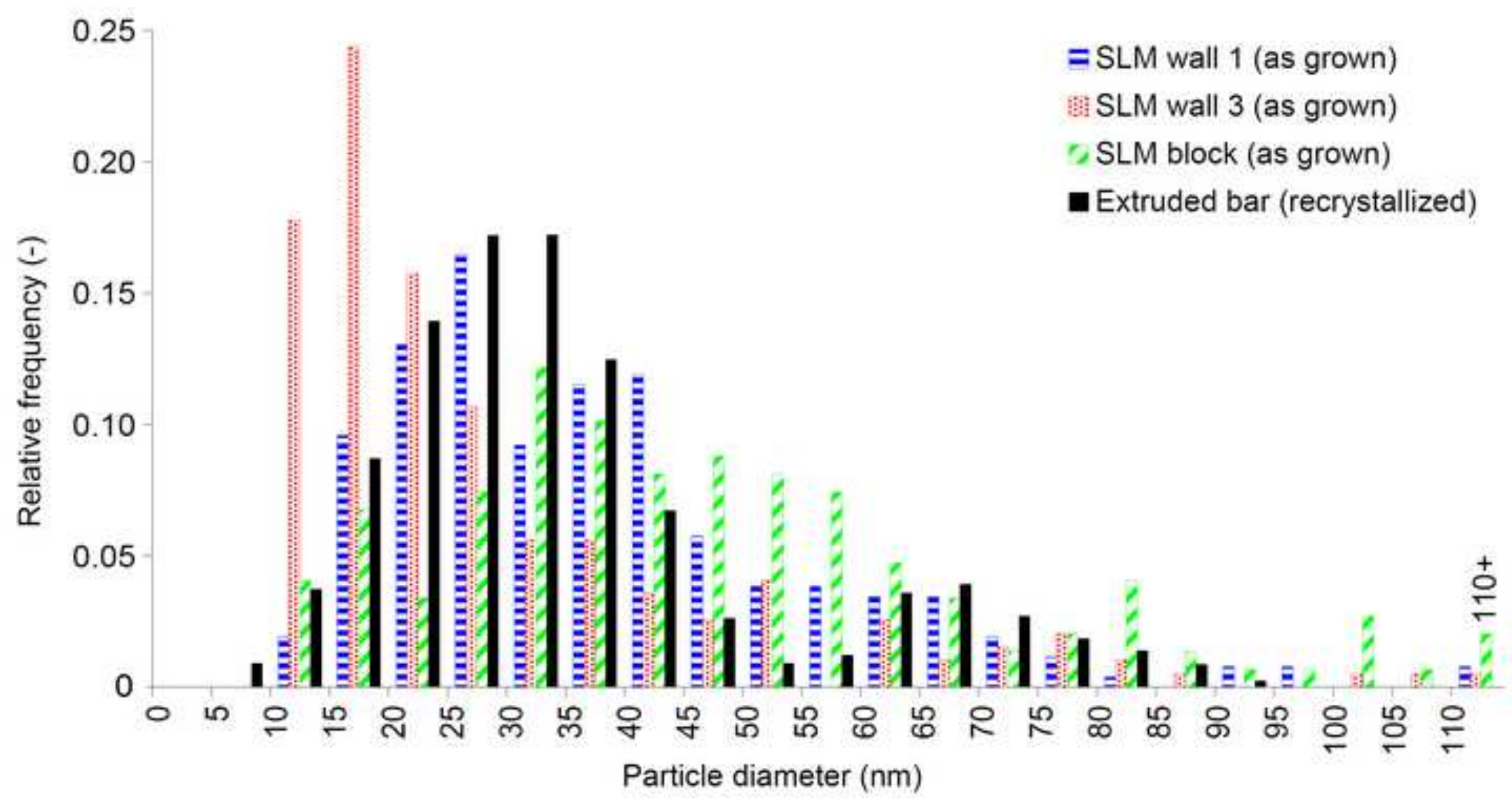




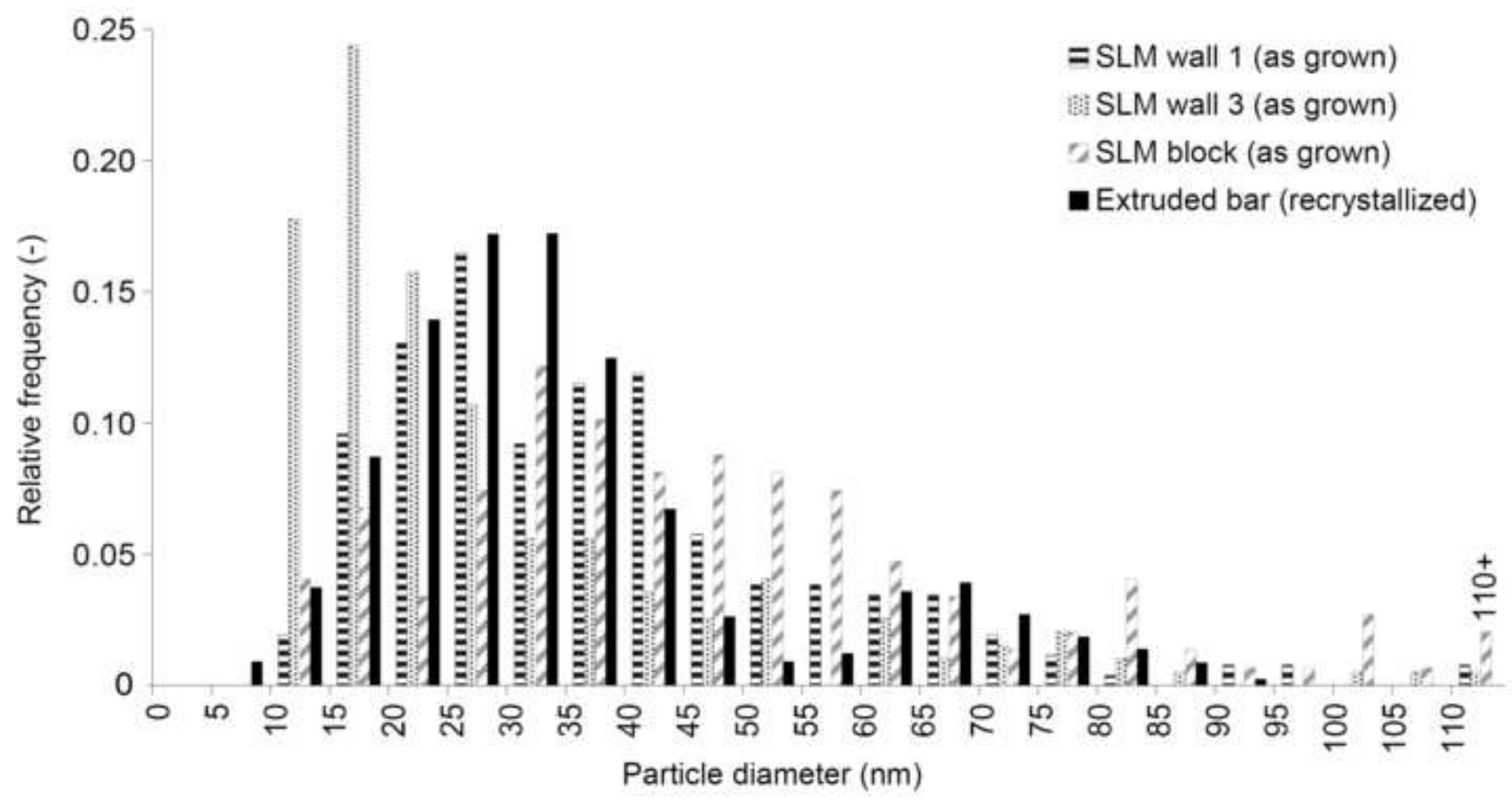



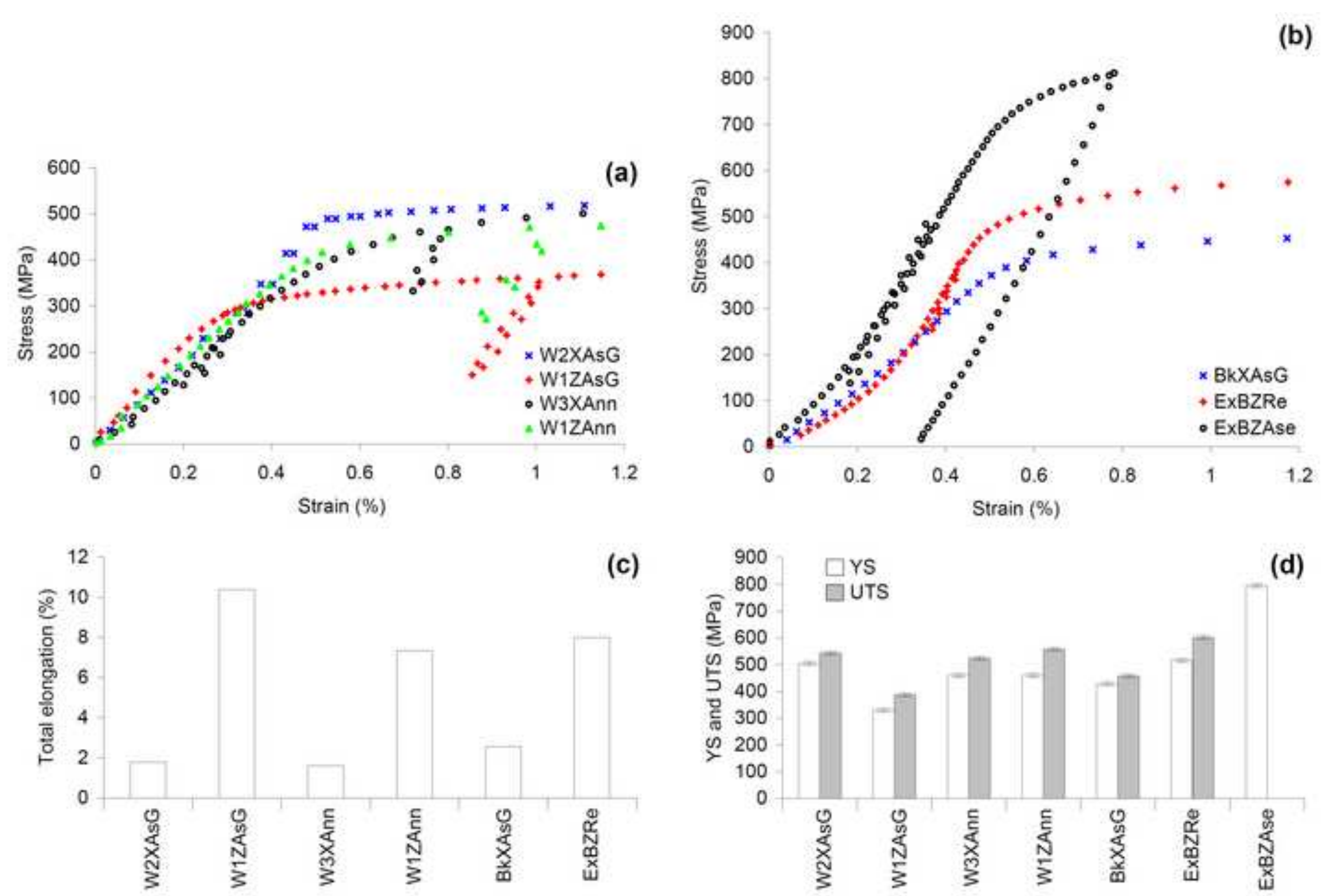

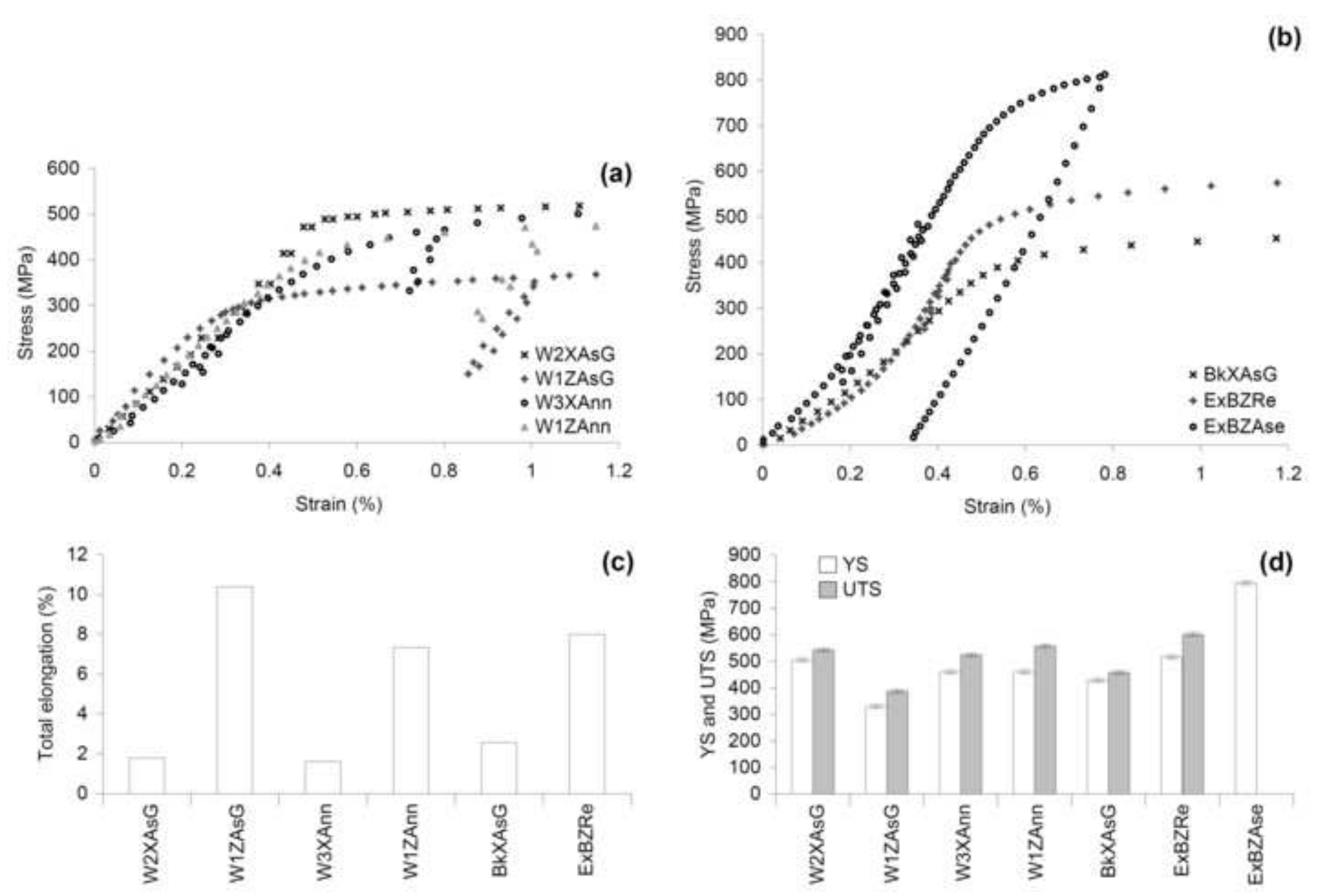
Figure 11 (web version), $11 / 2$ columns

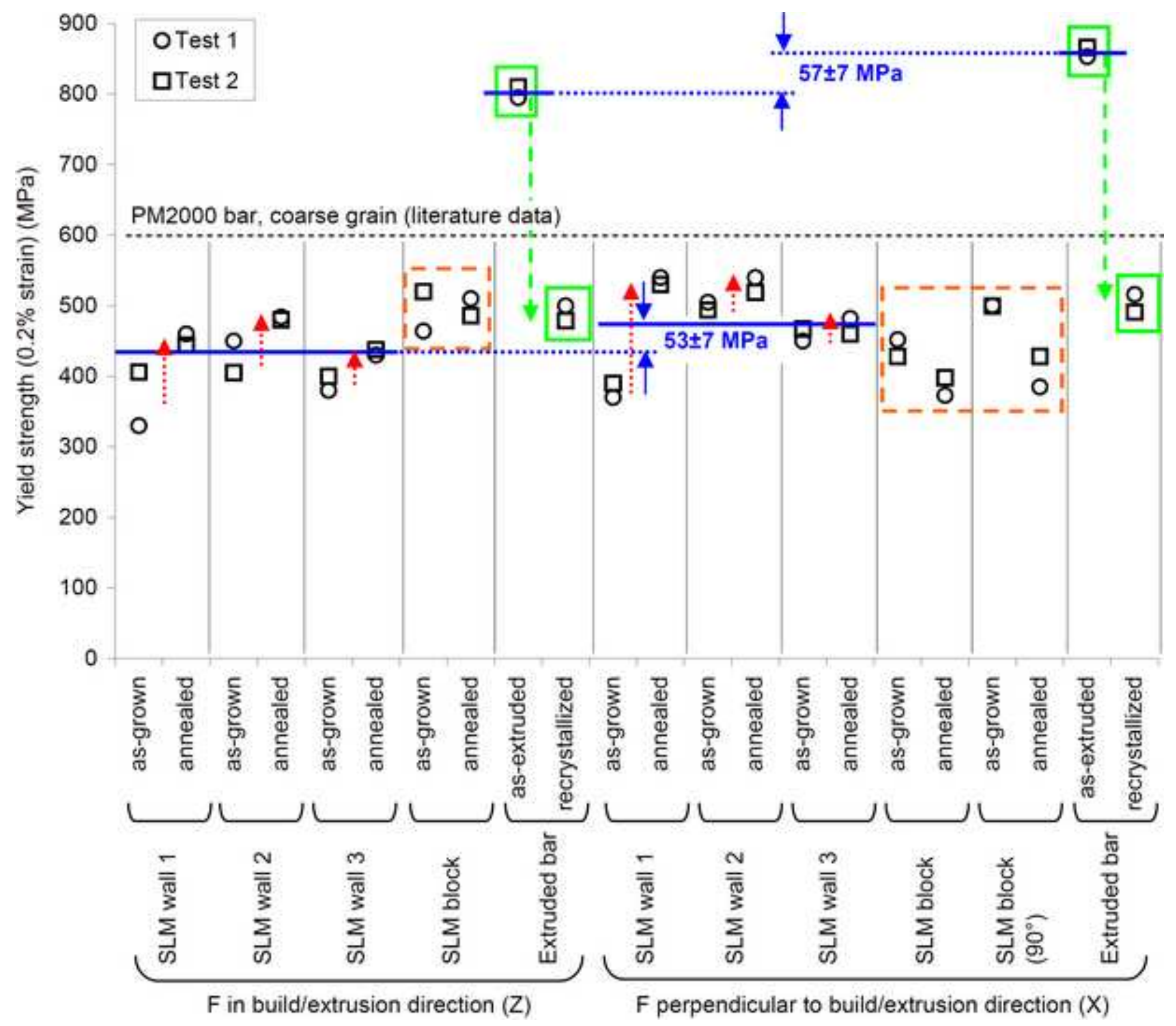


Figure 11 (print version), $11 / 2$ columns

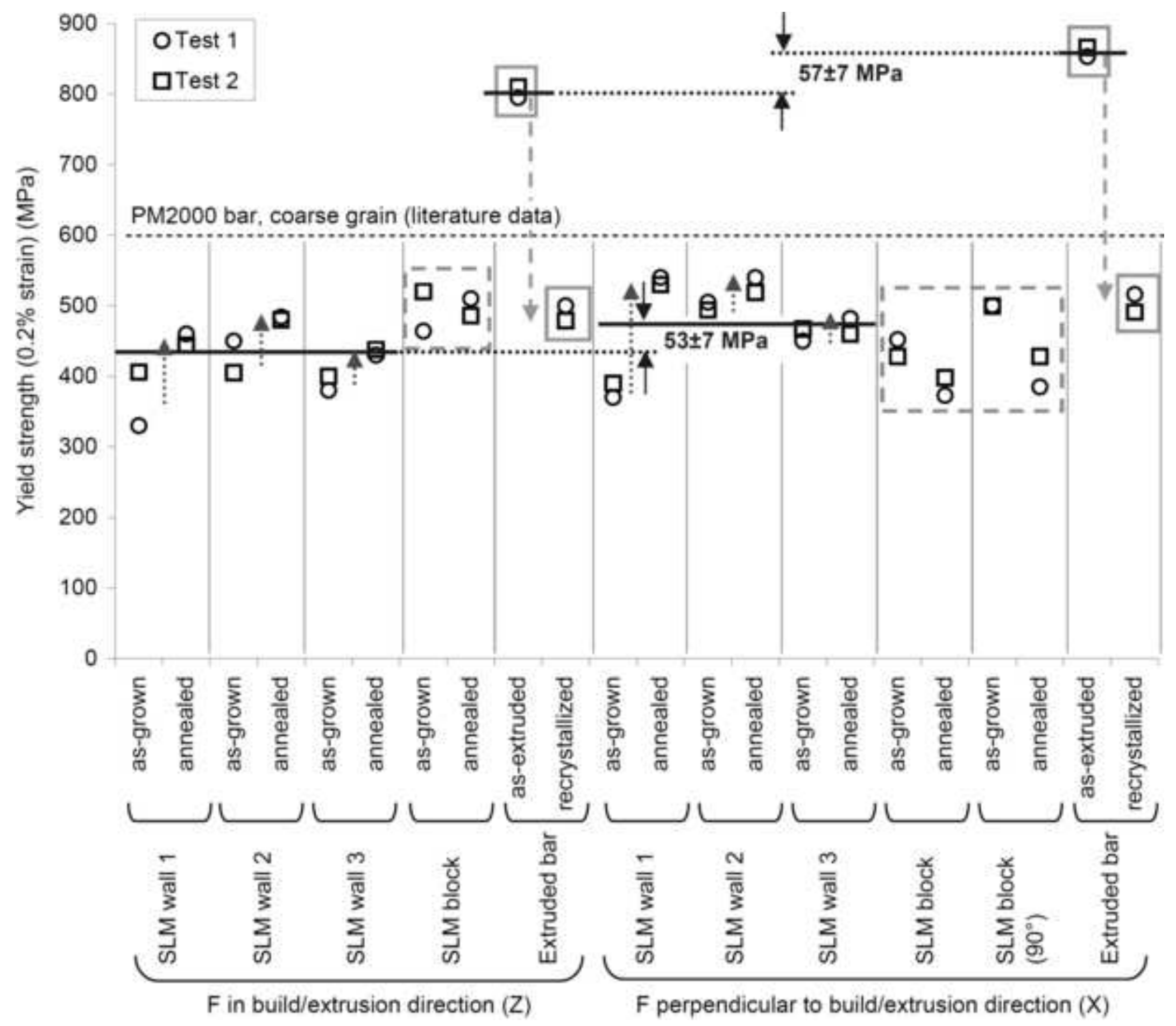




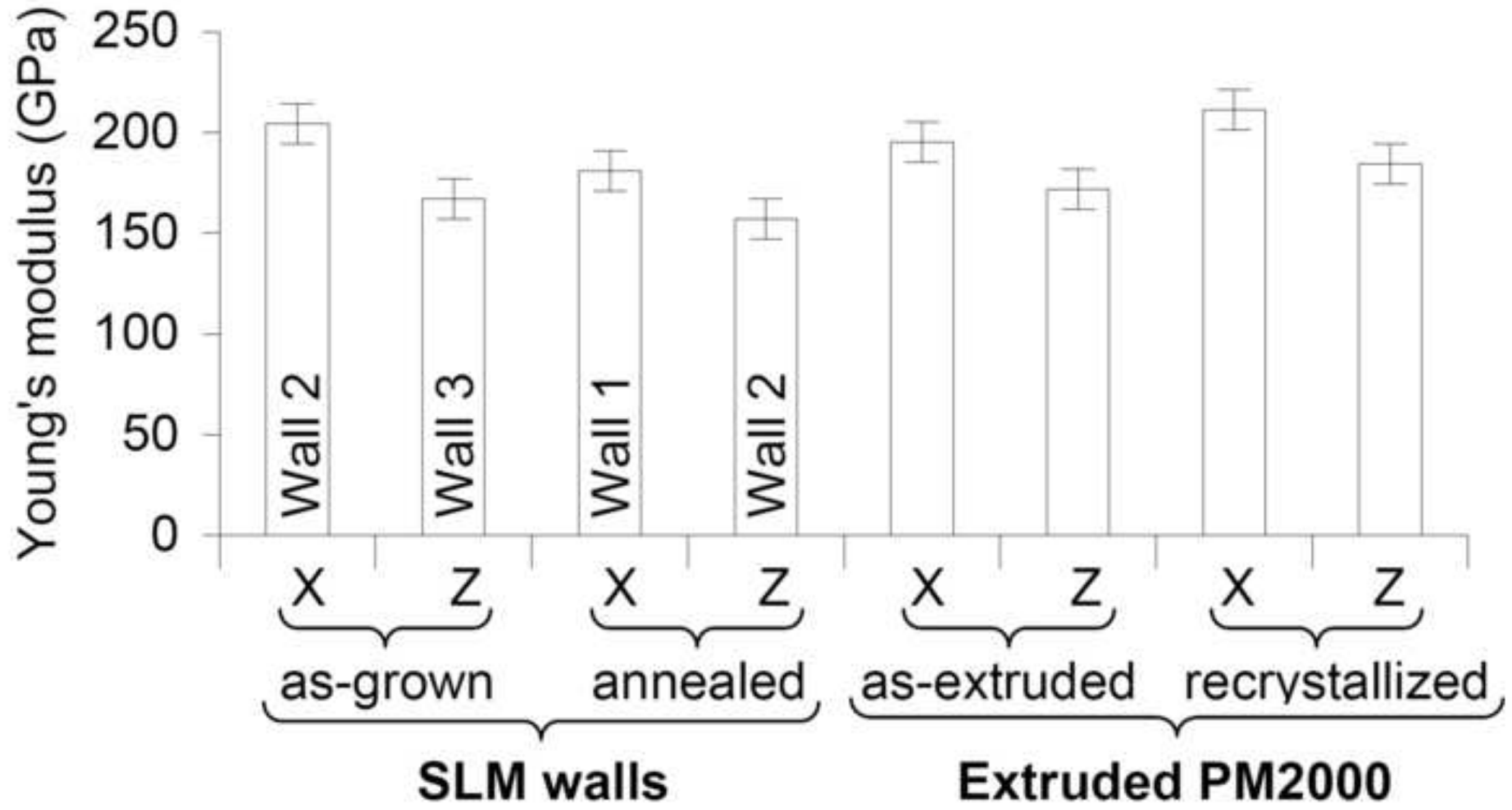



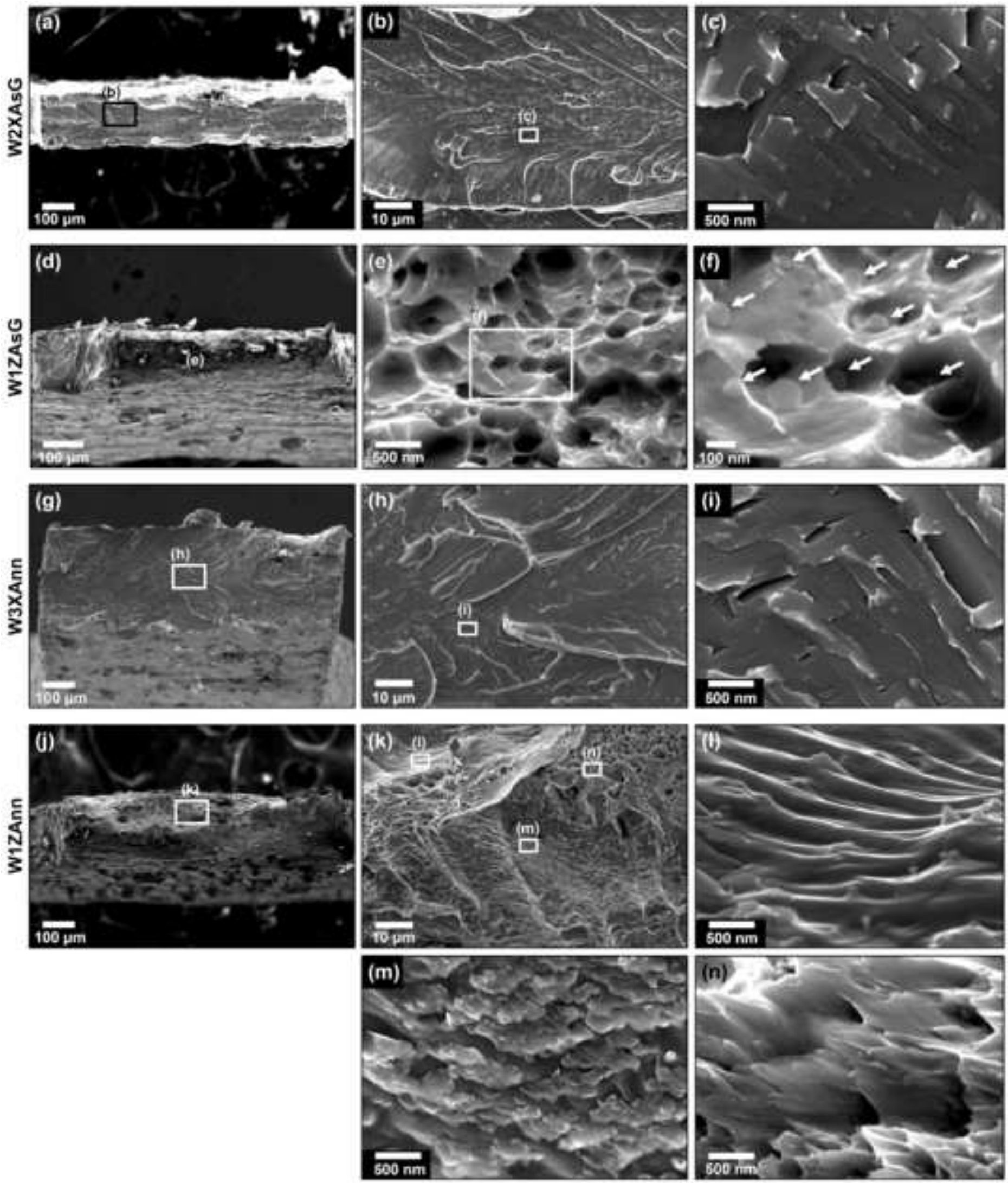

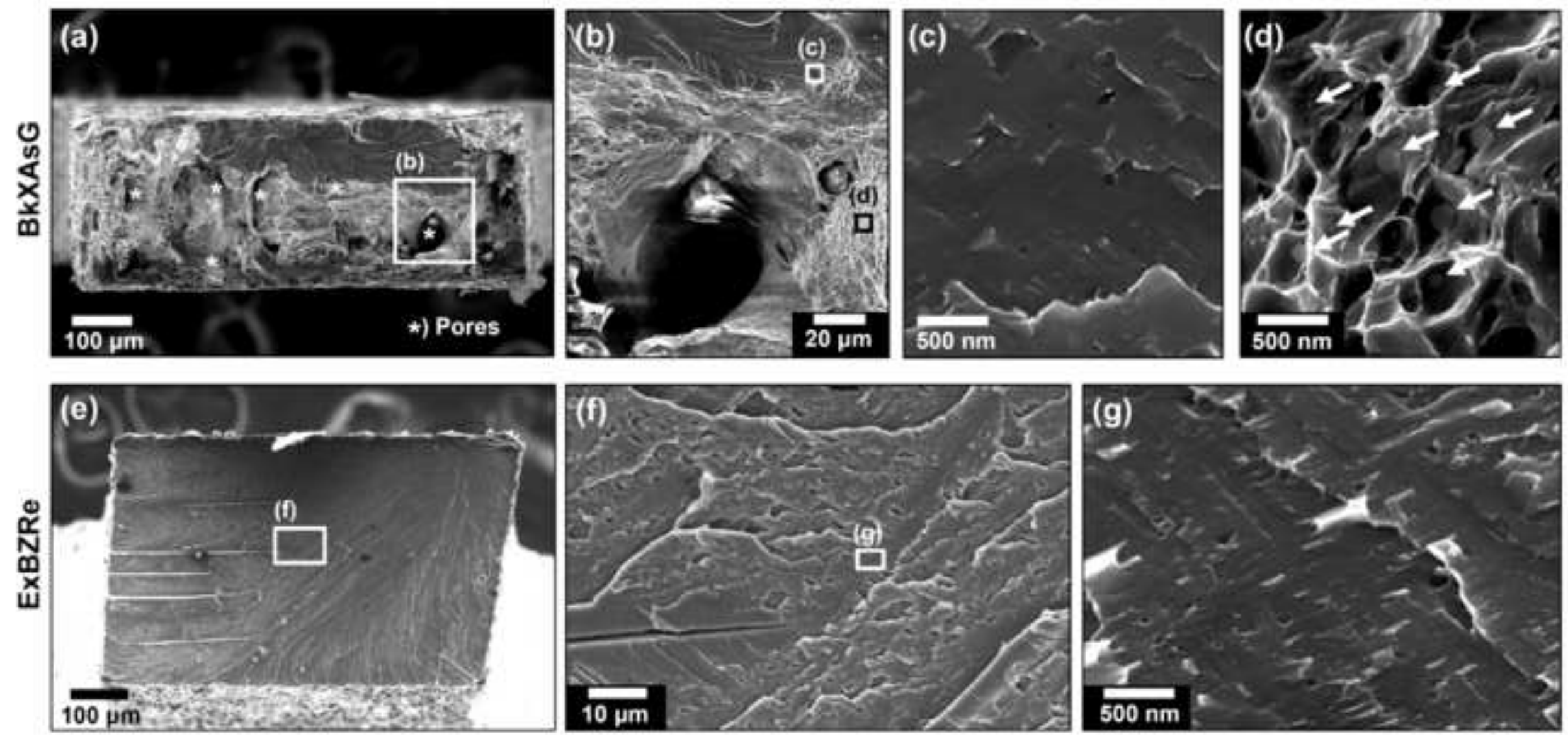
(a) W2XAsG

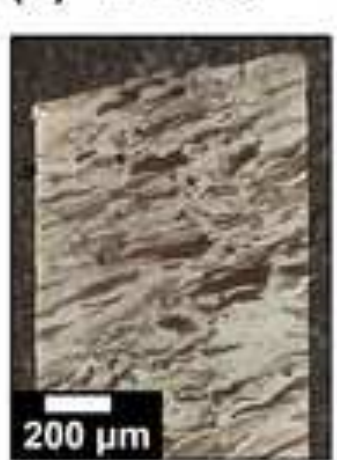

(c) W3XAnn

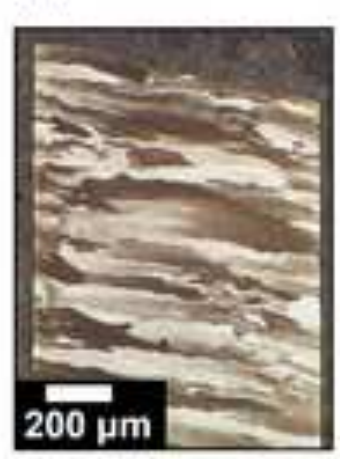

(e) BKXAsG

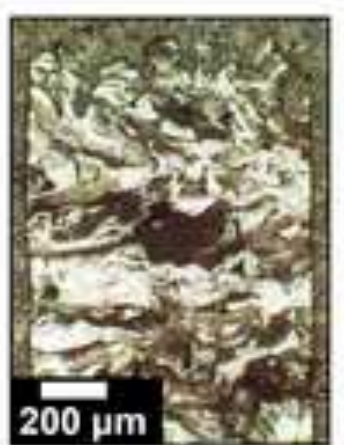

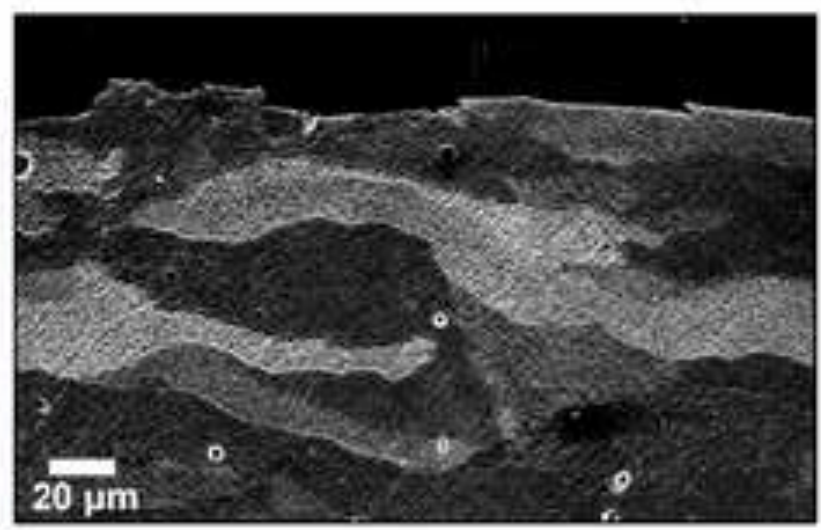
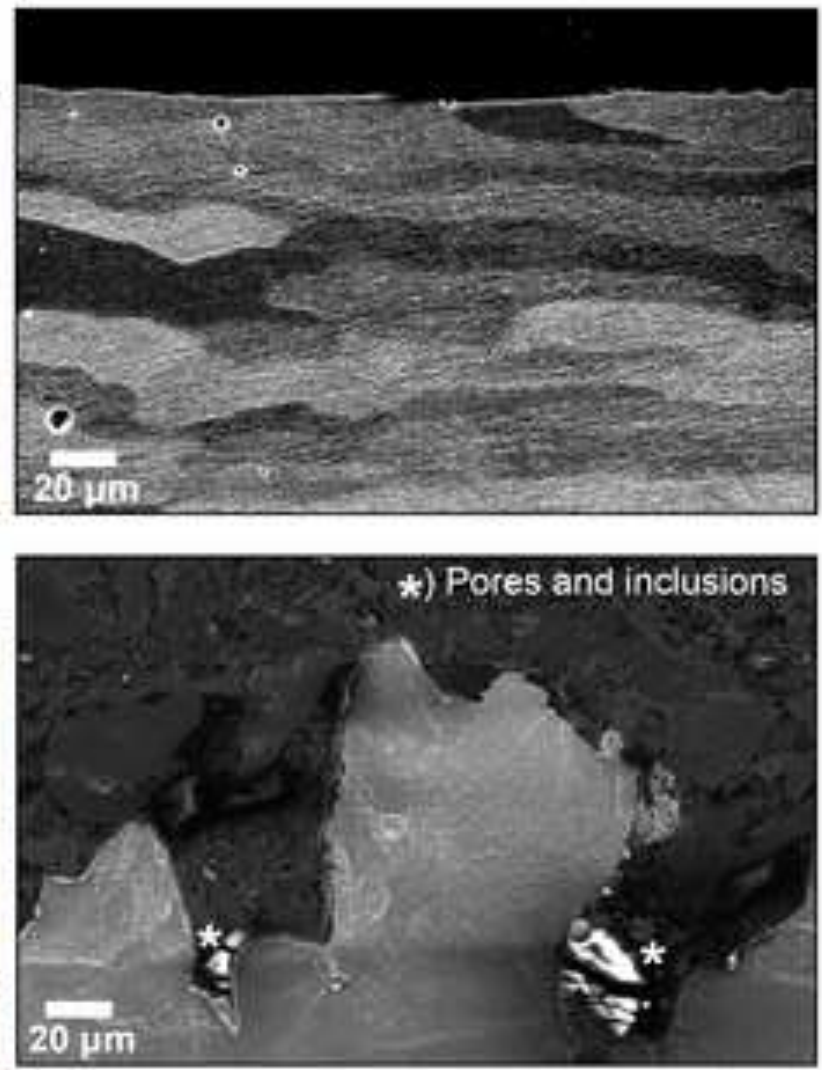

(b) W1ZAsG
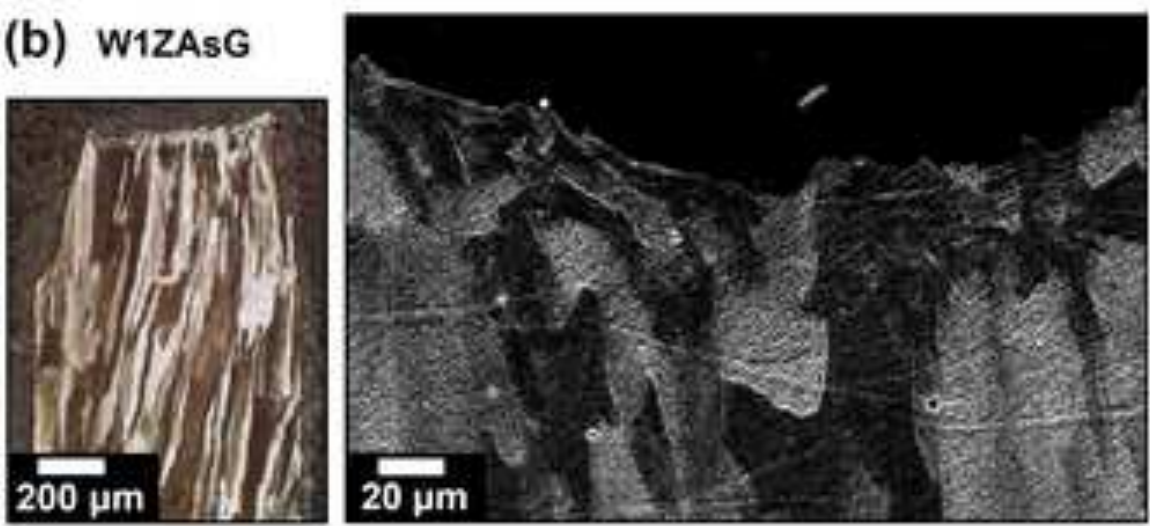

(d) W1ZAnn
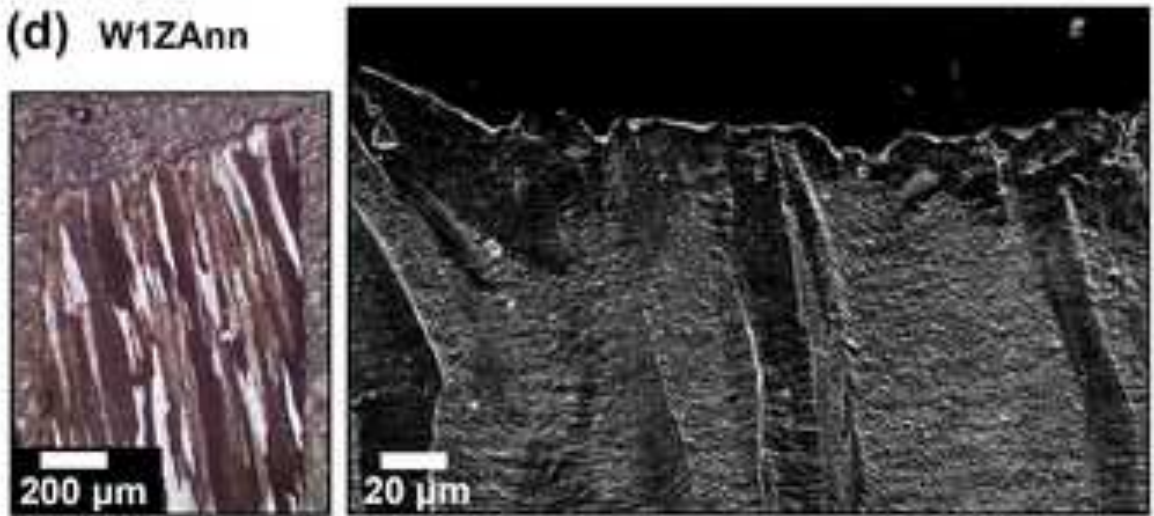

(f) ExBZRe

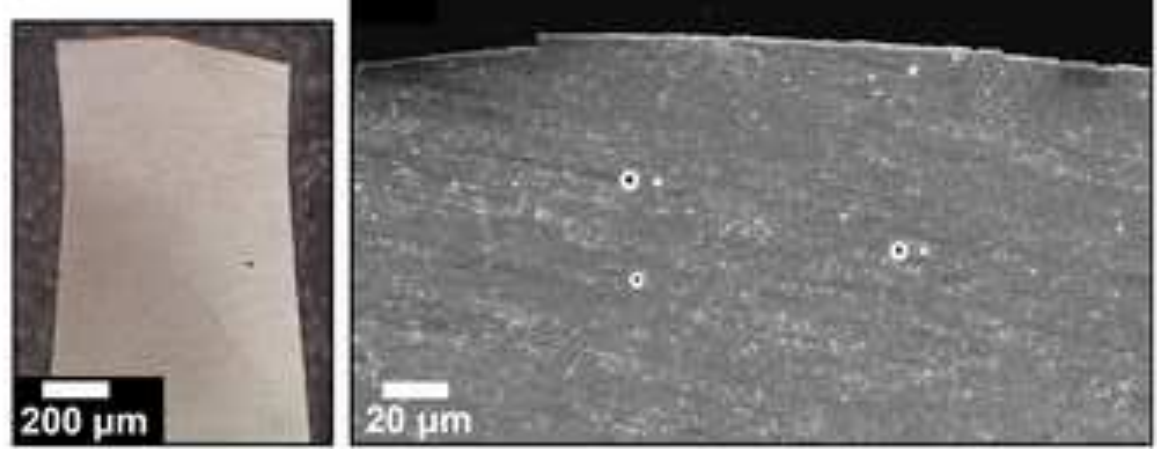


(a) W2XAsG

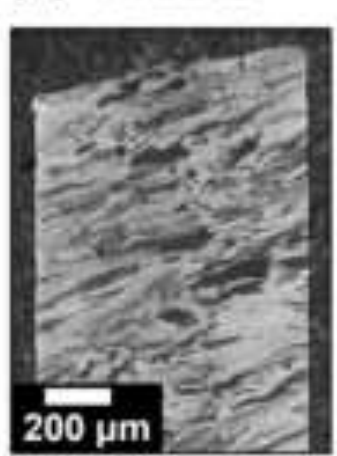

(c) W3XAnn

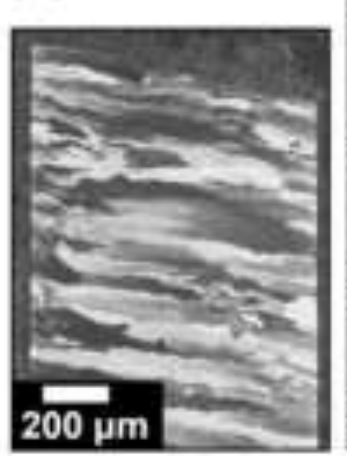

(e) BkXAsG

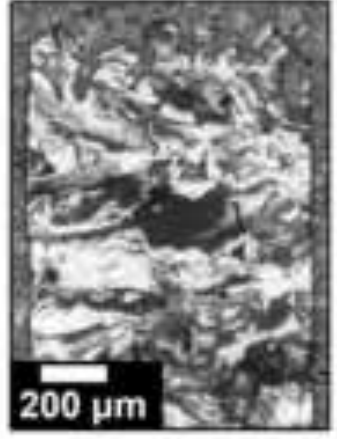

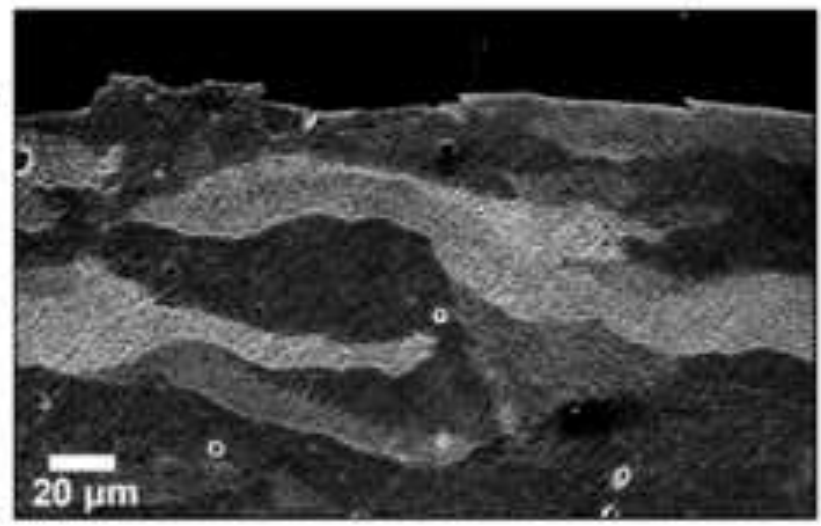
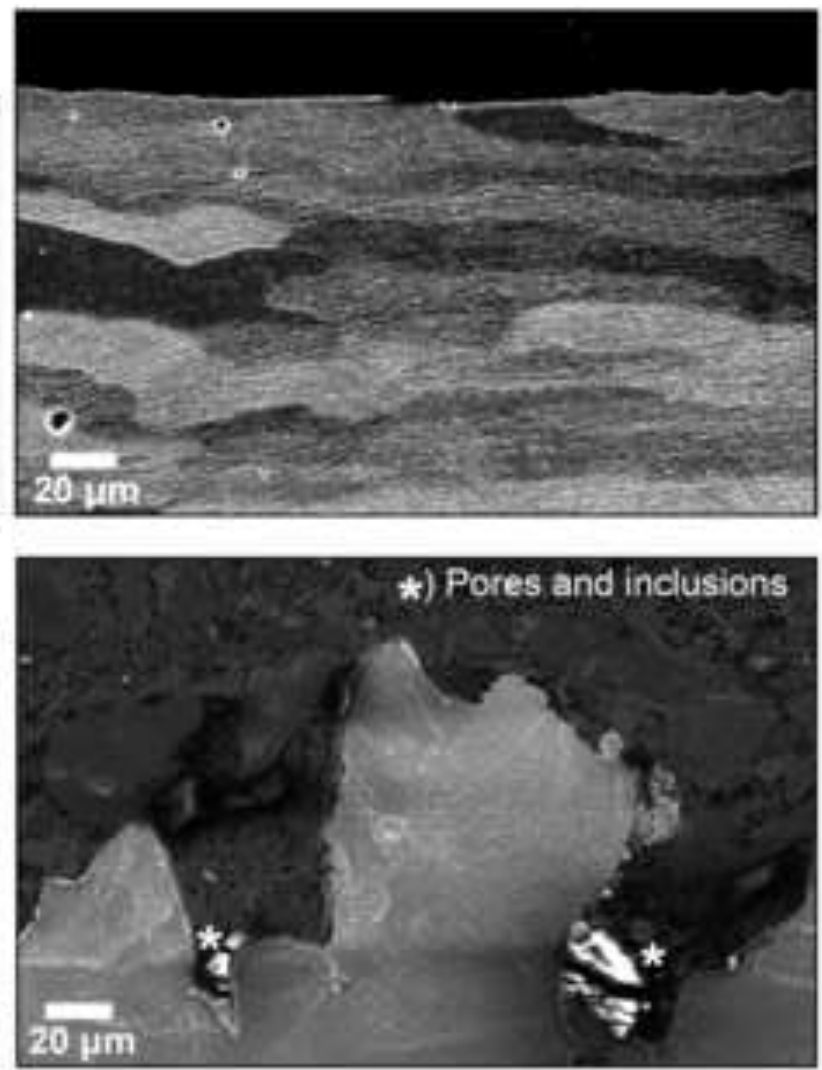

(b) W1ZAsG
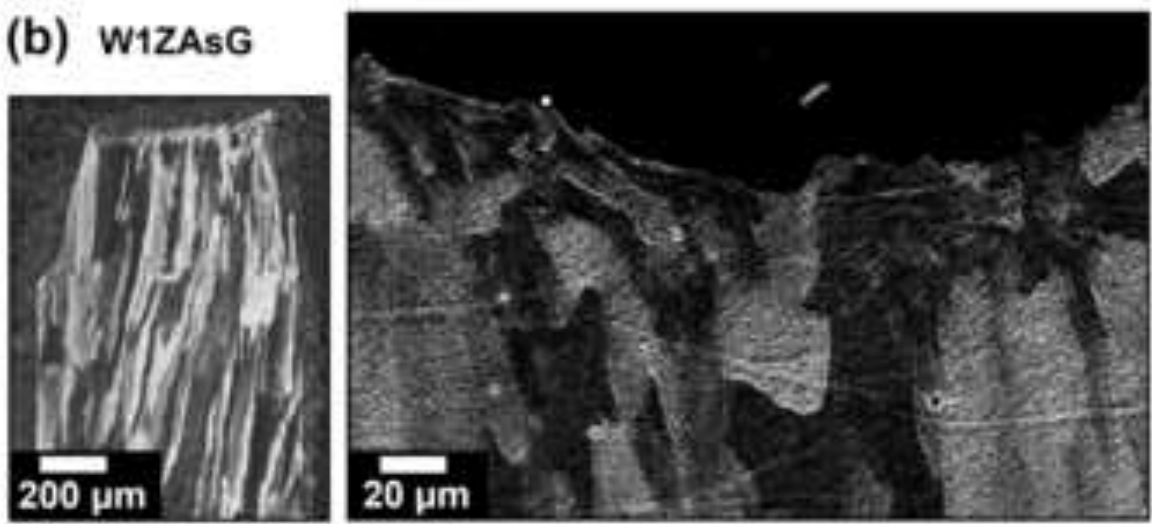

(d) WizAnn

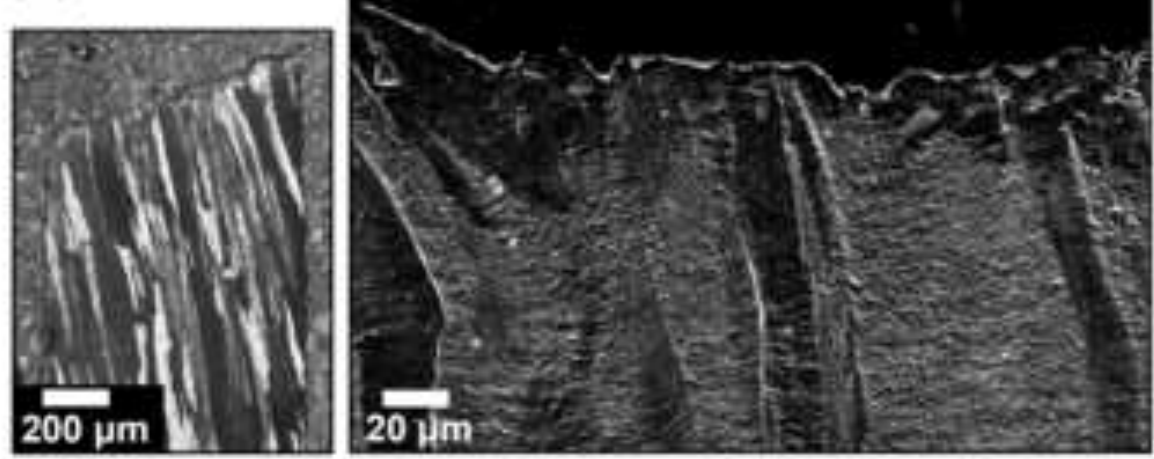

(f) ExBZRe

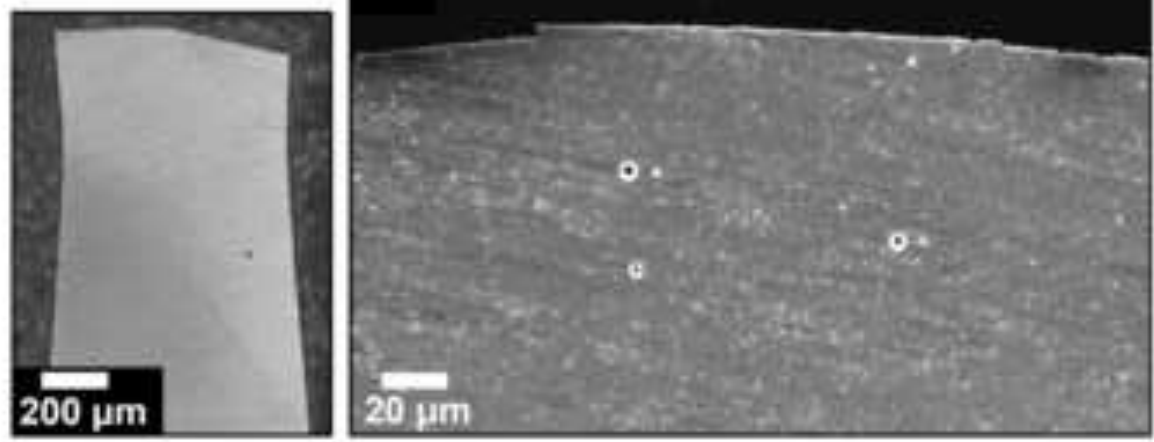


Table 1

\begin{tabular}{lllllllll}
\hline & $\mathrm{Fe}$ & $\mathrm{Al}$ & $\mathrm{Ti}$ & $\mathrm{Cr}$ & $\mathrm{Y}_{2} \mathrm{O}_{3}$ & $\mathrm{Y}$ & $\mathrm{O}$ & others \\
\hline $\mathrm{A}$ & balance & 5.5 & 0.5 & 19.0 & 0.5 & - & - & - \\
\hline $\mathrm{B}$ & 74.66 & 5.34 & 0.45 & 18.77 & - & 0.39 & 0.24 & $<0.15$ \\
\hline
\end{tabular}


Table 2

\begin{tabular}{llll}
\hline Abbreviation & Build configuration & Condition & Direction of test stress \\
\hline W2XAsG & SLM wall 2 & as-grown & X \\
\hline W1ZAsG & SLM wall 1 & as-grown & Z \\
\hline W3XAnn & SLM wall 3 & annealed & X \\
\hline W1ZAnn & SLM wall 1 & annealed & Z \\
\hline BkXAsG & SLM block & as-grown & X \\
\hline ExBZRe & Extruded bar & recrystallized & Z \\
\hline ExBZAse & Extruded bar & as-extruded & Z \\
\hline
\end{tabular}

